\title{
Nutritional status and dietary intakes of children aged 6 months to 12 years: findings of the Nutrition Survey of Malaysian Children (SEANUTS Malaysia)
}

\author{
Bee Koon Poh ${ }^{1 *}$, Boon Koon $\mathrm{Ng}^{1}$, Mohd Din Siti Haslinda ${ }^{2}$, Safii Nik Shanita ${ }^{3}$, Jyh Eiin Wong ${ }^{1}$, \\ Siti Balkis Budin ${ }^{4}$, Abd Talib Ruzita ${ }^{1}$, Lai Oon $\mathrm{Ng}^{5}$, Ilse Khouw ${ }^{6}$ and A. Karim Norimah ${ }^{1}$ \\ ${ }^{1}$ Nutritional Sciences Programme, Faculty of Health Sciences, School of Healthcare Sciences, Universiti Kebangsaan \\ Malaysia, 50300 Kuala Lumpur, Malaysia \\ ${ }^{2}$ Department of Statistics, Putrajaya, Malaysia \\ ${ }^{3}$ Dietetics Programme, Faculty of Health Sciences, School of Healthcare Sciences, Universiti Kebangsaan Malaysia, \\ Kuala Lumpur, Malaysia \\ ${ }^{4}$ Biomedical Sciences Programme, Faculty of Health Sciences, School of Diagnostics and Applied Health, Universiti \\ Kebangsaan Malaysia, Kuala Lumpur, Malaysia \\ ${ }^{5}$ Health Psychology Programme, Faculty of Health Sciences, Universiti Kebangsaan Malaysia, Kuala Lumpur, Malaysia \\ ${ }^{6}$ FrieslandCampina, Amersfoort, The Netherlands
}

(Submitted 18 September 2012 - Final revision received 13 February 2013 - Accepted 14 March 2013)

\section{Abstract}

The dual burden of malnutrition reportedly coexists in Malaysia; however, existing data are scarce and do not adequately represent the nutritional status of Malaysian children. The Nutrition Survey of Malaysian Children was carried out with the aim of assessing the nutritional status in a sample of nationally representative population of children aged 6 months to 12 years. A total of 3542 children were recruited using a stratified random sampling method. Anthropometric measurements included weight, height, mid-upper arm circumference, and waist and hip circumferences. Blood biochemical assessment involved analyses of $\mathrm{Hb}$, serum ferritin, and vitamins A and D. Dietary intake was assessed using semi-quantitative FFQ, and nutrient intakes were compared with the Malaysian Recommended Nutrient Intakes (RNI). The prevalence of overweight (9.8\%) and obesity (11.8\%) was higher than that of thinness (5.4\%) and stunting (8.4\%). Only a small proportion of children had low levels of $\mathrm{Hb}(6 \cdot 6 \%)$, serum ferritin (4.4\%) and vitamin A (4.4\%), but almost half the children (47.5\%) had vitamin D insufficiency. Dietary intake of the children was not compatible with the recommendations, where more than one-third did not achieve the Malaysian RNI for energy, Ca and vitamin D. The present study revealed that overnutrition was more prevalent than undernutrition. The presence of high prevalence of vitamin D insufficiency and the inadequate intake of Ca and vitamin D are of concern. Hence, strategies for improving the nutritional status of Malaysian children need to consider both sides of malnutrition and also put emphasis on approaches for the prevention of overweight and obesity as well as vitamin D insufficiency.

Key words: Children's nutritional status: Blood biochemistry: Dietary intakes: Double burden of malnutrition

Global transitions in economic development and sociodemography have resulted in dietary and lifestyle changes ${ }^{(1)}$, which in turn have implications for nutritional and health status of children around the world ${ }^{(2,3)}$. In many developing countries, including in Malaysia, it is known that the dual burden of malnutrition coexists ${ }^{(4-6)}$, sometimes within the same family ${ }^{(7)}$.

The World Health Statistics has reported that the percentage of underweight children aged $<5$ years declined globally from $25 \%$ in 1990 to $18 \%$ in $2005^{(8)}$, while the prevalence of overweight in the same age group averaged at $6.7 \%{ }^{(9)}$. Globally, one-third of pre-schoolers suffered from vitamin A deficiency in 1995-2005, with $45.5 \%$ of the prevalence being observed in Southeast Asia ${ }^{(10)}$. The problem of anaemia among Southeast Asian pre-school children was severe at $65.5 \%{ }^{(11)}$. More recently, vitamin D has also been recognised as a global problem ${ }^{(12)}$, with a large proportion of children reported among children worldwide, including in sun-rich countries $^{(13-16)}$.

Data from the National Health and Morbidity Survey (NHMS) III has revealed that the prevalences of stunting, underweight and overweight among children aged $<5$ years are $17.2,12.9$ and $6.4 \%$, respectively, in Malaysia ${ }^{(17)}$. Another follow-up survey has reported that the prevalence of

Abbreviations: NHMS, National Health and Morbidity Survey; RNI, Recommended Nutrient Intakes; SEANUTS, South East Asian Nutrition Survey.

*Corresponding author: Dr B. K. Poh, fax +60 32694 7621, email pbkoon@fsk.ukm.my 
underweight among school-aged children in Malaysia decreased slightly from $9 \cdot 7 \%$ in 2002 to $9.5 \%$ in 2008 , while that of overweight/obesity increased from 20.7 to $26.4 \%$ during the same period ${ }^{(18)}$. Anaemia has been observed in $32 \%$ of the pre-schoolers ${ }^{(19)}$, while vitamin A deficiency has been reported in $3.5 \%$ of the children aged $<5$ years in a rural area of the country (Ministry of Health/UNICEF (2000) Nutritional status of children under five years, unpublished results). Among school-aged children in the capital city, Kuala Lumpur, 35.3\% had low serum 25-hydroxyvitamin D concentrations indicative of vitamin D deficiency ${ }^{(16)}$.

Nutrition is an important influencing factor with regard to the continuous growth and development that occur throughout the childhood period. Although anthropometry is widely accepted as the most useful tool for assessing the nutritional status of children ${ }^{(20)}$, dietary assessment is also commonly used in epidemiological studies to monitor the nutritional status of children. The contribution of the various macronutrients and micronutrients to the diet is the major focus of studies on dietary intakes in children ${ }^{(21)}$. Evaluating dietary intake among children not only helps one to identify possible risk factors for diet-linked diseases but also allows researchers to examine whether food intake is influenced by non-modifiable factors such as sex, ethnicity and age ${ }^{(22)}$. In addition, using blood biochemical analyses to determine nutritional status can be extremely beneficial as they help one to assess and interpret lifestyle and dietary intakes. Deviations in blood chemistry are detectable before the symptoms of malnutrition manifest ${ }^{(23)}$. It is, therefore, useful in the prevention of diseases or early detection of malnutrition.

With this background, it is obvious that while nationwide anthropometric data are widely available as indicators of nutritional status in Malaysia, data on other nutrition and health indicators are scarce, especially for infants and young children aged $\leq 12$ years. Existing data do not adequately represent the nutritional status of Malaysian children, and reports are available only for specific sections of the population. Thus, the Nutrition Survey of Malaysian Children was carried out with the main aim of assessing the nutritional status in a sample of nationally representative population of Malaysian children aged 6 months to 12 years.

The present survey was part of the South East Asian Nutrition Survey (SEANUTS), a multi-centre study that was simultaneously carried out among 16744 children aged 0.5-12 years in four countries, namely Indonesia, Malaysia, Thailand and Vietnam. Comprehensive assessment of nutritional status was undertaken, which included anthropometry, body composition, dietary intake, physical activity and blood biochemistry, as well as assessment of bone health and cognitive function $^{(24)}$. The present study describes only the key results for anthropometry, body composition, blood biochemistry and dietary intake from the Nutrition Survey of Malaysian Children.

\section{Methodology}

\section{Study design and sampling}

The present cross-sectional study was conducted from May 2010 till October 2011 throughout Malaysia. A stratified random sampling of children aged 0.5-12.9 years from a random sample selection of schools, kindergartens and nurseries in Malaysia, stratified for geographical location and age, was carried out. The present study was carried out on a region-based sample. Data collection was done in all six regions, namely Northern, Central, Southern and East Coast in Peninsular Malaysia and Sabah and Sarawak (map shown in Fig. 1). The sampling process is shown in Fig. 2.

The sample size was calculated using a formula for the estimation of a population proportion with a specified relative precision $^{(25)}$ as follows:

$$
n=Z_{1-\alpha / 2}^{2} \frac{(1-p)}{p \cdot \varepsilon^{2}}
$$

where $n$ is the required sample size, $Z_{1-\alpha / 2}$ is the value of the standard normal distribution at the desired CI, $p$ is the estimated prevalence of the variable of interest and $\varepsilon$ is the relative precision required.

The prevalence of childhood overweight in Malaysia, which is $5.4 \%$ as reported by the NHMS III ${ }^{(26)}$, was chosen

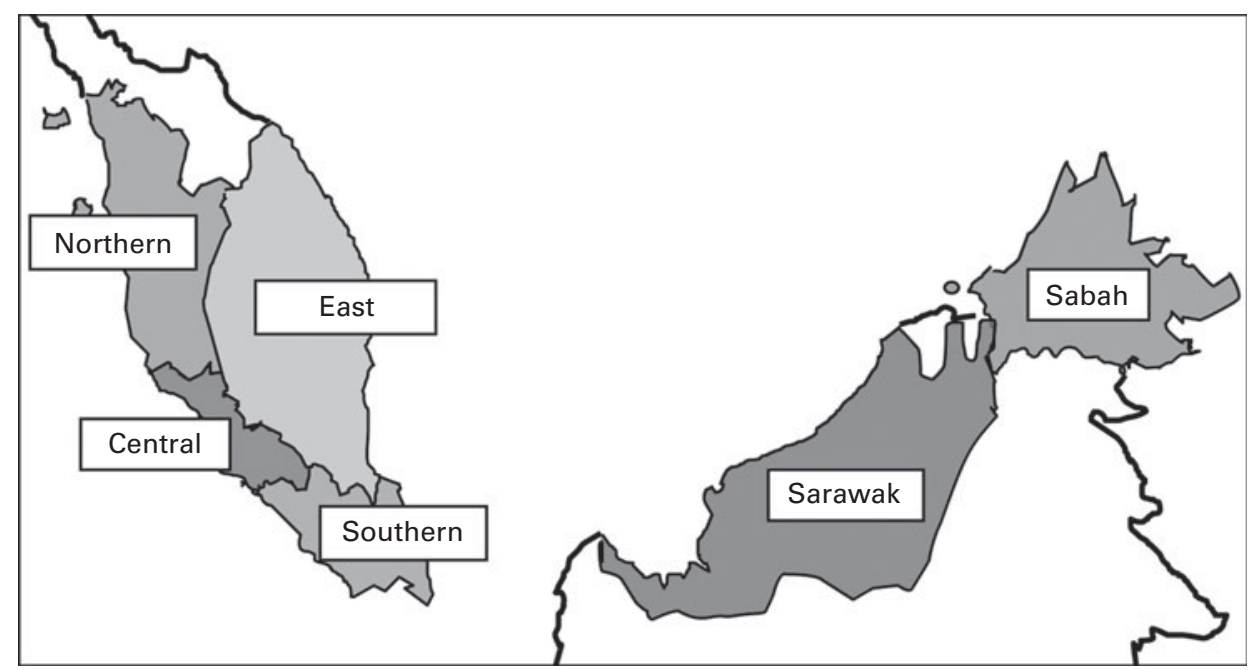

Fig. 1. Map of Malaysia showing the six regions. 


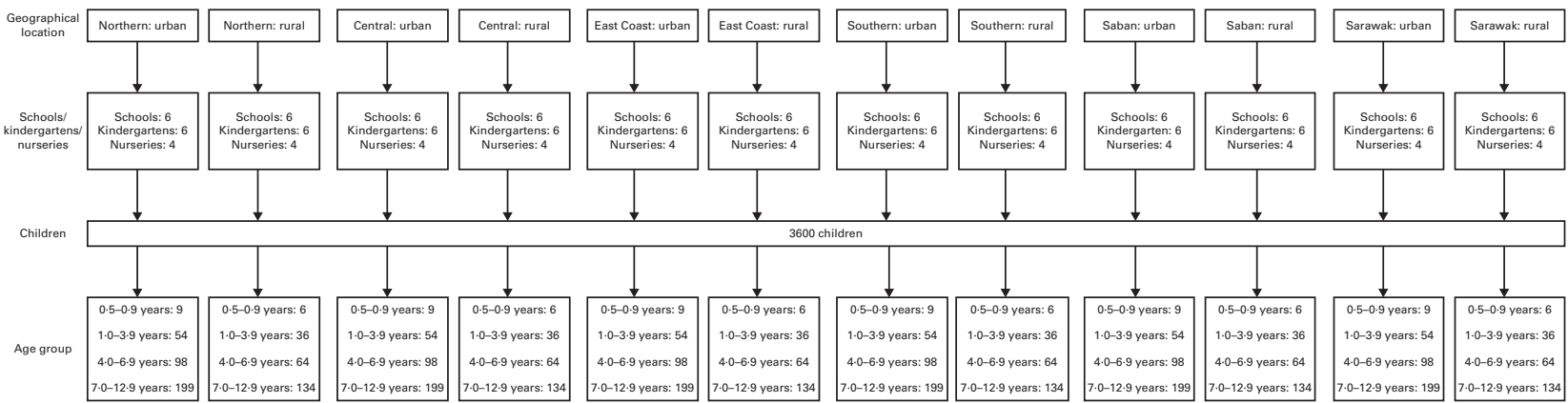

Fig. 2. Sampling process scheme.

as the main study variable $(p)$. At a confidence level of $95 \%$ and a $15 \%$ level of precision, the sample size required for the study was 2991. Taking into account a non-response rate of $20 \%$, the required sample size was increased to 3589 and was rounded up to 3600 . The allocation of children was unequally proportionate to the geographical location with the ratio of 3:2 for urban and rural areas, respectively ${ }^{(27)}$.

In Malaysia, children start compulsory schooling at the age of 7 years, and before that, many attend kindergartens or nurseries for pre-school education or day care. Therefore, recruitment was done at nurseries and kindergartens for those aged $\leq 6$ years and at primary schools for those aged $>6$ years. The proportions of children enrolled in primary school and pre-school were 96 and $67 \%$, respectively ${ }^{(28)}$, while the proportion of children attending nurseries was unknown, but estimated to be approximately $25 \%$. The lists for nurseries, kindergartens and school were obtained from the Ministry of Education, the Department of Social Welfare and the Department of Community Development. Permission to carry out data collection was granted by the relevant authorities of each of the selected premises.

\section{Subjects}

Subjects comprised both boys and girls and all the main ethnic groups in Malaysia, namely Malays, Chinese and Indians as well as Sabah and Sarawak natives. In the present study, no differentiation was made between the ethnic groups. Inclusion criteria were apparently healthy Malaysian children aged 6 months to 12 years, not physically handicapped and without obvious genetic disorders. Children who were ill or were absent on the day of measurements were excluded from the study. Subjects were grouped into four age groups, namely infants $(0.5-0.9$ years), toddlers ( $1.0-3.9$ years), pre-schoolers (4.0-6.9 years) and school-aged children ( $7 \cdot 0-12$ years).

The present study was conducted according to the guidelines laid down in the Declaration of Helsinki, and all procedures involving human subjects were approved by the Research Ethics Committee of Universiti Kebangsaan Malaysia. Written informed consent was obtained from the parents or guardians of all the subjects, and verbal assent was obtained from each child before data collection. The present trial was registered in the Dutch Trial Registry as NTR2462.

\section{Data collection procedure}

A set of questionnaires with detailed instructions, including a FFQ, was given to and completed by the mother or main carer of the subjects. A day before data collection, parents were informed by the data collection team about the time when the measurements would be taken and reminded to dress their children in sports uniform, usually comprising a T-shirt and a pair of shorts or track pants. On the day of measurements, the FFQ were collected and checked for completeness, and, where necessary, telephone calls were made to the parent or carer to verify the information provided. Guided by a team of researchers and enumerators, the subjects were assigned to three measurement stations: weight and height station; skinfold and circumference station; body composition station in an enclosed measurement room. Every subject was given the results of measurements, a small gift and a certificate of participation at the end of the study.

\section{Anthropometric measurements}

All anthropometric measurements were carried out by three research assistants who were trained and certified in the International Society for the Advancement of Kinanthropometry $\operatorname{method}^{(29)}$. Measurements were carried out in children in light clothing and without shoes. All measurements were taken twice and the mean was calculated. If the difference between two measurements was more than $10 \%$, a third measurement was taken and the median was used.

Body weight was measured with a SECA digital weighing scale Model 803 (SECA) to the nearest $0 \cdot 1 \mathrm{~kg}$, while height was measured with a portable SECA stadiometer Model 213 (SECA) to the nearest $0 \cdot 1 \mathrm{~cm}$. BMI was calculated by dividing the measured weight $(\mathrm{kg})$ by the square of height $(\mathrm{m})$.

Anthropometric status was classified using the WHO growth standards for $0-5$ years ${ }^{(30)}$ and the WHO growth reference for 5-19 years ${ }^{(31)}$. $z$-Scores for weight-for-age, height-for-age, BMI-for-age and weight-for-height were determined using the software WHO Anthro version 3.1.0 (32) (World Health Organisation, Geneva, Switzerland) for children aged $\leq 5$ years. For children aged $>5$ years, the WHO AnthroPlus version 1.0.3 $3^{(33)}$ (World Health Organisation, Geneva, Switzerland) software was used to determine the $z$-scores for weight-for-age, height-for-age and BMI-for-age. The cut-off 
values for wasting, stunting and thinness were $-2 \mathrm{sD}$. On the other hand, the cut-off values for overweight and obesity among children aged $<5$ years were $2 \mathrm{sD}$, whereas they were $1 \mathrm{SD}$ and $2 \mathrm{SD}$, respectively, among children aged $>5$ years as recommended by the $\mathrm{WHO}^{(30,31)}$.

Mid-upper arm circumference and waist and hip circumferences were measured with a Lufkin tape (Model W606PM; Apex Tool Group) to the nearest $0.1 \mathrm{~cm}$. In addition, head circumference was measured among children aged $\leq 3$ years. Tricipital and subscapular skinfolds were measured in all the subjects with a Harpenden skinfold calliper (British Indicators Limited) to the nearest $0.1 \mathrm{~mm}$.

\section{Blood biochemical assessments}

Blood sampling was carried out within a week of the anthropometric measurements. Approximately $6 \mathrm{ml}$ of venous blood were drawn from the subjects aged $\geq 2$ years by trained phlebotomists. The collected blood samples were kept in a standard storage box with an ice pack and transported immediately to an accredited laboratory for analysis. Blood samples were analysed for $\mathrm{Hb}$ and serum ferritin as well as vitamins A and D.

$\mathrm{Hb}$ concentration was measured by a spectrophotometric technique using Sysmex XE5000 (Sysmex), while serum ferritin concentration was measured by a two-site sandwich immunoassay using a direct chemiluminescence method using ADVIA Centaur (Siemens). Vitamin D concentration through the measurement of 25-hydroxyvitamin D was measured by a direct competitive chemiluminescence method using the Diaspora Liaison vitamin D platform (Diasorin). Vitamin A concentration through the measurement of serum retinol was determined by HPLC using Agilent 1100 HPLC (Agilent).

The values obtained through the blood tests were then compared with the internationally acceptable cut-off values to determine deficiencies. $\mathrm{Hb}$ concentration was used to determine anaemia, whereas serum ferritin concentration as the single best predictor of Fe deficiency ${ }^{(34)}$ was used to determine Fe deficiency. Anaemia was defined as Hb concentrations $<110 \mathrm{~g} / 1$ for children aged $<5$ years, $<115 \mathrm{~g} / \mathrm{l}$ for children aged 5-11.9 years and $<120 \mathrm{~g} / 1$ for children aged $\geq 12$ years $^{(35)}$. Fe deficiency was defined as serum ferritin concentrations $<12 \mu \mathrm{g} / 1$ for children aged $<5$ years and $<15 \mu \mathrm{g} / 1$ for children aged $\geq 5$ years ${ }^{(36)}$. Serum retinol concentration
$<0.70 \mu \mathrm{mol} / 1$ was used as an indication for vitamin $\mathrm{A}$ deficiency $^{(10)}$, whereas circulating 25-hydroxyvitamin D concentration $<50 \mathrm{nmol} / \mathrm{l}$ was used as an indication for vitamin D insufficiency ${ }^{(37)}$.

\section{Assessment of dietary intake}

Dietary intake was assessed using semi-quantitative FFQ, with parents or carers as the proxy for children. According to three different age groups, three different sets of FFQ were developed and validated for the children: FFQ1 for children aged 6-23 months ${ }^{(38,39)}$; FFQ2 for those aged $2-6$ years $^{(40)}$; FFQ3 for those aged $7-12$ years ${ }^{(41,42)}$. In brief, the validation study results attested to a good acceptance of the FFQ. The mean intakes of the macronutrients were comparable between the FFQ and 3-days dietary record (3DR) methods, although those assessed by the FFQ method tended to be higher. Correlations between the two methods were moderate and ranged from $r 0.310$ and $P<0.001$ for fat to $r 0.497$ and $P<0.001$ for energy. As indicated by Cronbach's $\alpha$ coefficients ranging between 0.61 (protein) and 0.70 (energy, carbohydrate and fat), the FFQ exhibited a good reliability when administered a week apart.

FFQ1, FFQ2 and FFQ3 consisted of seventy-six, ninety-five and ninety-four food items, respectively. These food items were grouped into thirteen food groups, namely cereals and cereal products, meat and meat products, fish and seafood, eggs, legumes and legume products, milk and dairy products, vegetables, fruit, confectionery, beverages, spreads, seasonings and flavouring, and soups. The frequency of intake and amount of habitual food consumption of the children were collated. The eight frequency categories were 'never', '1-3 times a month', 'once a week', '2-4 times a week', '5-6 times a week', 'once a day', '2-3 times a day' and ' 4 times or more a day'. Each food item in the FFQ was assigned a portion size using common household units, such as plate, bowl and tablespoon. To facilitate accurate reporting, written instructions on how to fill in the FFQ were provided and photographs of food portion sizes were given in a separate booklet.

Nutrient values for each food item were obtained from the Nutrient Composition of Malaysian Foods ${ }^{(43)}$, Composition of Foods Commonly Eaten in Singapore ${ }^{(44)}$ and food product labels. The nutrient value of breast milk, an item listed in

Table 1. Number of children who participated in the study by age group

\begin{tabular}{|c|c|c|c|c|c|c|c|c|c|c|}
\hline & \multicolumn{2}{|c|}{$0.5-0.9$ years } & \multicolumn{2}{|c|}{$1.0-3.9$ years } & \multicolumn{2}{|c|}{$4.0-6.9$ years } & \multicolumn{2}{|c|}{$7 \cdot 0-12$ years } & \multicolumn{2}{|c|}{ Total } \\
\hline & $\begin{array}{l}\text { Sample } \\
(n)\end{array}$ & $\begin{array}{l}\text { Estimated } \\
\text { population } \\
\qquad(n)\end{array}$ & $\begin{array}{l}\text { Sample } \\
(n)\end{array}$ & $\begin{array}{l}\text { Estimated } \\
\text { population } \\
\qquad(n)\end{array}$ & $\begin{array}{l}\text { Sample } \\
(n)\end{array}$ & $\begin{array}{l}\text { Estimated } \\
\text { population } \\
(n)\end{array}$ & $\begin{array}{c}\text { Sample } \\
(n)\end{array}$ & $\begin{array}{l}\text { Estimated } \\
\text { population } \\
(n)\end{array}$ & $\begin{array}{c}\text { Sample } \\
\text { (n) }\end{array}$ & $\begin{array}{c}\text { Estimated } \\
\text { population } \\
(n)\end{array}$ \\
\hline \multicolumn{11}{|l|}{ Urban } \\
\hline Boys & 20 & 70680 & 150 & 544783 & 324 & 583937 & 558 & 1192061 & 1052 & 2391461 \\
\hline Girls & 23 & 65913 & 144 & 511612 & 268 & 535735 & 615 & 1170900 & 1050 & 2284160 \\
\hline All & 43 & 136593 & 294 & 1056395 & 592 & 1119672 & 1173 & 2362961 & 2102 & 4675621 \\
\hline \multicolumn{11}{|l|}{ Rural } \\
\hline Boys & 9 & 6962 & 128 & 173349 & 185 & 119157 & 388 & 312718 & 710 & 612186 \\
\hline Girls & 16 & 8838 & 116 & 175463 & 190 & 138333 & 408 & 287731 & 730 & 610365 \\
\hline All & 25 & 15800 & 244 & 348812 & 375 & 257490 & 796 & 600449 & 1440 & 1222551 \\
\hline
\end{tabular}


Table 2. Anthropometric characteristics of boys and girls by age group (Mean values with their standard errors)

\begin{tabular}{|c|c|c|c|c|c|c|c|c|c|c|c|c|c|c|c|c|}
\hline \multirow[b]{3}{*}{ Variables } & \multicolumn{4}{|c|}{$0.5-0.9$ years } & \multicolumn{4}{|c|}{$1.0-3.9$ years } & \multicolumn{4}{|c|}{$4.0-6.9$ years } & \multicolumn{4}{|c|}{$7 \cdot 0-12 \cdot 0$ years } \\
\hline & \multicolumn{2}{|c|}{ Boys } & \multicolumn{2}{|c|}{ Girls } & \multicolumn{2}{|c|}{ Boys } & \multicolumn{2}{|c|}{ Girls } & \multicolumn{2}{|c|}{ Boys } & \multicolumn{2}{|c|}{ Girls } & \multicolumn{2}{|c|}{ Boys } & \multicolumn{2}{|c|}{ Girls } \\
\hline & Mean & SE & Mean & SE & Mean & SE & Mean & SE & Mean & SE & Mean & SE & Mean & SE & Mean & SE \\
\hline \multicolumn{17}{|l|}{ Urban } \\
\hline Age (years) & 0.77 & 0.03 & 0.77 & 0.03 & 2.58 & 0.08 & 2.53 & 0.08 & $5 \cdot 51$ & 0.05 & 5.50 & 0.06 & 9.94 & 0.10 & 9.97 & 0.09 \\
\hline Weight $(\mathrm{kg})$ & $8 \cdot 1$ & 0.2 & 7.9 & 0.2 & $12 \cdot 5$ & 0.2 & $12 \cdot 3$ & 0.1 & 19.5 & 0.3 & $18 \cdot 8$ & 0.3 & $35.0 \dagger$ & 0.6 & $35 \cdot 2 \dagger$ & 0.6 \\
\hline Height $(\mathrm{cm})$ & $70 \cdot 3$ & 0.6 & $69 \cdot 2$ & 0.7 & 88.7 & 0.4 & 88.6 & 0.3 & $110 \cdot 7$ & 0.3 & $110 \cdot 1$ & 0.3 & $135.5 \dagger$ & 0.3 & $136 \cdot 8^{\star \star}+\dagger$ & 0.3 \\
\hline $\operatorname{BMI}\left(\mathrm{kg} / \mathrm{m}^{2}\right)$ & $16 \cdot 4$ & 0.3 & $16 \cdot 6$ & 0.5 & $15 \cdot 8$ & $0 \cdot 1$ & $15 \cdot 5$ & $0 \cdot 1$ & $15 \cdot 7$ & 0.2 & $15 \cdot 4$ & 0.2 & 18.5 & 0.2 & $18.3 \dagger$ & 0.2 \\
\hline Arm circumference $(\mathrm{cm})$ & $14 \cdot 3$ & 0.3 & $14 \cdot 2$ & 0.2 & $15 \cdot 4$ & 0.1 & $15 \cdot 4$ & 0.1 & $17 \cdot 3$ & 0.2 & $17 \cdot 1$ & 0.2 & 21.5 & 0.2 & $21.6 \dagger$ & 0.2 \\
\hline Head circumference $(\mathrm{cm})$ & 43.6 & 0.3 & 43.0 & 0.2 & $47 \cdot 8^{\star \star}$ & 0.2 & $47 \cdot 1$ & 0.1 & - & - & - & - & - & - & - & - \\
\hline Waist circumference $(\mathrm{cm})$ & $42 \cdot 8$ & 0.7 & $42 \cdot 3$ & 0.5 & $46 \cdot 3$ & 0.3 & $46 \cdot 5$ & 0.3 & $52 \cdot 1^{*}$ & 0.4 & $50 \cdot 7$ & 0.4 & $63 \cdot 2^{\star \star} \dagger$ & 0.6 & $60 \cdot 7 \dagger$ & 0.6 \\
\hline Hip circumference $(\mathrm{cm})$ & $42 \cdot 8$ & 0.8 & 43.6 & 0.6 & $48 \cdot 6$ & 0.3 & $49 \cdot 4$ & 0.4 & $57 \cdot 6$ & 0.4 & $58 \cdot 2$ & 0.4 & $73.0 \dagger$ & 0.5 & $74.9^{* *} \dagger$ & 0.5 \\
\hline Tricipital skinfold (mm) & $10 \cdot 0$ & 0.6 & $10 \cdot 0$ & 0.6 & $9 \cdot 1+\dagger \dagger$ & 0.2 & $9 \cdot 3^{\star \star \star} \dagger$ & 0.2 & 9.5 & 0.3 & $10 \cdot 1$ & 0.2 & $13 \cdot 2 \dagger$ & 0.4 & $14 \cdot 1$ & 0.3 \\
\hline Subscapular skinfold (mm) & $7 \cdot 2$ & 0.6 & $7 \cdot 8$ & 0.5 & $5 \cdot 7$ & 0.2 & $6 \cdot 5^{\star \star}$ & 0.2 & $7 \cdot 0$ & 0.3 & $7 \cdot 8^{*}$ & 0.3 & 11.5 & 0.4 & $13 \cdot 2^{\star *}$ & 0.4 \\
\hline Sum of the two skinfolds $(\mathrm{mm})$ & $17 \cdot 3$ & 1.0 & 17.9 & 1.0 & $14 \cdot 8$ & 0.4 & $15 \cdot 8^{\star}$ & 0.3 & $16 \cdot 5$ & 0.5 & $17 \cdot 8$ & 0.5 & $24.7 \dagger$ & 0.7 & $27 \cdot 3^{*}$ & 0.7 \\
\hline \multicolumn{17}{|l|}{ Rural } \\
\hline Age (years) & $0.88 \dagger$ & 0.04 & 0.81 & 0.05 & $2 \cdot 73$ & 0.12 & 2.74 & 0.12 & $5.72 \dagger$ & 0.07 & $5 \cdot 67$ & 0.06 & $10 \cdot 21$ & 0.14 & $10 \cdot 15$ & 0.15 \\
\hline Weight $(\mathrm{kg})$ & 9.5 & 1.0 & $7 \cdot 6$ & 0.2 & $13 \cdot 0^{\star \star}$ & 0.2 & $12 \cdot 2$ & 0.2 & 19.5 & 0.5 & 18.5 & 0.4 & $32 \cdot 7$ & 0.8 & 32.5 & 1.0 \\
\hline Height $(\mathrm{cm})$ & 74.2 & 3.0 & 70.5 & $2 \cdot 2$ & $88 \cdot 7$ & 0.4 & 88.0 & 0.3 & 109.8 & 0.5 & 109.4 & 0.4 & 134.7 & 0.5 & 134.6 & 0.6 \\
\hline $\mathrm{BMI}\left(\mathrm{kg} / \mathrm{m}^{2}\right)$ & $17 \cdot 0$ & $1 \cdot 1$ & $15 \cdot 9$ & 0.5 & $16 \cdot 3^{\star \star} \dagger$ & 0.2 & $15 \cdot 7$ & 0.2 & $15 \cdot 9$ & 0.3 & $15 \cdot 2$ & 0.2 & $17 \cdot 6$ & 0.3 & 17.4 & 0.3 \\
\hline Arm circumference $(\mathrm{cm})$ & $15 \cdot 1^{*}$ & 0.4 & $14 \cdot 0$ & 0.2 & $15 \cdot 7$ & 0.2 & $15 \cdot 4$ & 0.2 & $17 \cdot 2$ & 0.3 & $17 \cdot 2$ & 0.2 & $20 \cdot 4$ & 0.3 & $20 \cdot 5$ & 0.3 \\
\hline Head circumference $(\mathrm{cm})$ & 44.7 & 0.9 & $42 \cdot 8$ & 0.6 & $47 \cdot 8^{*}$ & 0.2 & $47 \cdot 3$ & 0.2 & - & - & - & - & - & - & - & - \\
\hline Waist circumference $(\mathrm{cm})$ & 43.7 & $1 \cdot 2$ & $42 \cdot 2$ & 0.7 & $46 \cdot 7$ & 0.4 & $46 \cdot 2$ & $0 . \overline{3}$ & $52 \cdot 1^{\star *}$ & 0.7 & 49.9 & 0.5 & $60 \cdot 6$ & 0.8 & 58.5 & 0.8 \\
\hline Hip circumference $(\mathrm{cm})$ & $42 \cdot 6$ & $1 \cdot 8$ & $42 \cdot 7$ & 0.6 & 49.5 & 0.4 & 48.9 & 0.4 & $57 \cdot 6$ & 0.6 & $58 \cdot 0$ & 0.5 & $70 \cdot 8$ & 0.7 & $72 \cdot 5$ & 0.8 \\
\hline Tricipital skinfold (mm) & 9.9 & 0.5 & $9 \cdot 3$ & 0.4 & $8 \cdot 8$ & 0.2 & 8.6 & 0.2 & 9.7 & 0.4 & 9.9 & 0.3 & 11.8 & 0.5 & $13 \cdot 6^{*}$ & 0.5 \\
\hline Subscapular skinfold (mm) & $7 \cdot 2$ & 0.9 & $7 \cdot 3$ & 0.3 & $6 \cdot 2$ & 0.2 & $6 \cdot 7$ & 0.2 & 6.9 & 0.5 & $8 \cdot 3^{*}$ & 0.4 & $10 \cdot 1$ & 0.6 & $12 \cdot 2^{\star \star}$ & 0.5 \\
\hline Sum of the two skinfolds ( $\mathrm{mm}$ ) & $17 \cdot 2$ & 1.0 & $16 \cdot 6$ & 0.7 & 14.9 & 0.4 & $15 \cdot 2$ & 0.4 & $16 \cdot 6$ & 0.9 & $18 \cdot 2$ & 0.7 & 21.9 & $1 \cdot 1$ & $25 \cdot 8^{\star \star}$ & 1.0 \\
\hline
\end{tabular}

Mean values were significantly different between the boys and girls of each stratum based on ANCOVA after correcting for age: ${ }^{*} P<0.05 ;{ }^{* *} P<0.01 ;{ }^{* \star *} P<0.001$.

Mean values were significantly different between the urban and rural children of each sex based on ANCOVA after correcting for age: $\dagger P<0.05 ; \dagger+P<0.01 ; \dagger+\dagger P<0.001$. 
Table 3. Percentage of thinł, overweight and obese boys and girls in urban and rural areas by age group

\begin{tabular}{|c|c|c|c|c|c|c|c|c|c|c|c|c|c|c|c|}
\hline & \multicolumn{3}{|c|}{$0.5-0.9$ years } & \multicolumn{3}{|c|}{$1.0-3.9$ years } & \multicolumn{3}{|c|}{$4.0-6.9$ years } & \multicolumn{3}{|c|}{$7 \cdot 0-12$ years } & \multicolumn{3}{|c|}{ All } \\
\hline & Boys & Girls & All & Boys & Girls & All & Boys & Girls & All & Boys & Girls & All & Boys & Girls & All \\
\hline \multicolumn{16}{|l|}{ Urban } \\
\hline Thin & 11.4 & $4 \cdot 8$ & 8.2 & 2.9 & 1.7 & $2 \cdot 4$ & $7 \cdot 2^{*}$ & $2 \cdot 5$ & $5 \cdot 0$ & $7 \cdot 6$ & $5 \cdot 2$ & $6 \cdot 4$ & $6 \cdot 5^{\star}$ & $3 \cdot 8$ & $5 \cdot 2$ \\
\hline Overweight & $2 \cdot 4$ & $5 \cdot 0$ & 3.6 & $4 \cdot 1$ & $2 \cdot 7$ & 3.4 & $5 \cdot 8$ & $7 \cdot 4$ & 6.6 & $13 \cdot 3$ & $15 \cdot 6$ & 14.4 & 9.0 & $10 \cdot 5$ & 9.7 \\
\hline Obese & - & 11.3 & $5 \cdot 4^{\mathrm{a}, \mathrm{b}}$ & $1 \cdot 2^{*}$ & 0.1 & $0.7^{\mathrm{a}}$ & $12 \cdot 8^{*}$ & $5 \cdot 8$ & $9 \cdot 4^{\mathrm{b}}$ & $23 \cdot 5^{\star} \dagger$ & $16 \cdot 7$ & $20 \cdot 1^{b}$ & $15 \cdot 1^{* *}+\dagger$ & $10 \cdot 2$ & $12 \cdot 7$ \\
\hline \multicolumn{16}{|l|}{ Rural } \\
\hline Thin & $14 \cdot 2$ & - & $6 \cdot 2$ & $2 \cdot 1$ & 0.3 & 1.2 & 4.0 & $5 \cdot 7$ & 4.9 & $7 \cdot 6$ & $11 \cdot 1$ & $9 \cdot 3$ & 5.4 & $6.6 \dagger$ & $6 \cdot 0$ \\
\hline Overweight & $26 \cdot 4$ & - & 11.6 & 7.9 & $2 \cdot 7$ & $5 \cdot 3$ & 11.6 & $7 \cdot 8$ & 9.5 & $11 \cdot 2$ & $14 \cdot 2$ & $12 \cdot 6$ & 10.5 & $9 \cdot 2$ & 9.9 \\
\hline Obese & - & - & - & 1.2 & 0.4 & $0.8^{\mathrm{a}}$ & 8.8 & 6.5 & $7 \cdot 6^{\mathrm{b}}$ & $15 \cdot 4$ & $10 \cdot 4$ & $13 \cdot 0^{b}$ & 9.9 & 6.5 & $8 \cdot 2$ \\
\hline
\end{tabular}

${ }^{a, b}$ Mean values with unlike superscript letters were significantly different between the age groups based on complex sample logistic regression adjusted for age: $P<0.05$. Mean values were significantly different between the sexes by stratum based on complex sample logistic regression adjusted for age: ${ }^{\star} P<0.05 ;{ }^{\star \star} P<0.01$. Mean values were significantly different between the strata by sex based on complex sample logistic regression adjusted for age: $\dagger P<0.05$; $\dagger \dagger P<0.01$.

$\ddagger$ Thinness was calculated based on BMI-for-age $z$-scores $<-2$ SD.

FFQ1, was estimated at $11.3 \mathrm{ml} / \mathrm{min}^{(45)}$ and its nutrient content was obtained from the Association of Southeast Asian Nations (ASEAN) Food Composition Tables ${ }^{(46)}$. Total energy and nutrient intakes were calculated by employing an Excel-based platform ${ }^{(47)}$. The total energy and nutrient intake values were compared with the Recommended Nutrient Intakes (RNI) for Malaysia $^{(48)}$

\section{Statistical analyses}

Data were entered, cleaned and checked before data analysis. Double data entry was done for $10 \%$ of the data. Descriptive statistics are presented as means with their standard errors or percentage of prevalence. The children were stratified into four age groups, namely $0.5-0.9$ years, $1.0-3.9$ years, $4 \cdot 0-6 \cdot 9$ years and $7 \cdot 0-12 \cdot 9$ years. The adjusted means and standard errors were reported after adjusting for complex sampling and covariates including age and sex. Generalised linear models were used to calculate the adjusted means and standard errors of means of anthropometric and body composition measurements, blood parameters and nutrient intakes. Mean value differences were assessed using the Wald $F$ logistics regression for comparing prevalence or proportion with adjustment for complex sampling and covariates of age and sex. Statistical analyses were conducted using SPSS-IBM (version 16.0) (IBM Corporation, New York, United States of America) with a complex sampling module. A two-sided $P$ value of $<0.05$ was considered statistically significant.

\section{Results}

Table 1 reports the number of children in whom measurements were carried out and the estimated weighted population represented from the survey. A total of 3542 children participated in the study, representing an estimated population totalling 5898172 children aged 6 months to 12 years.

The anthropometric characteristics are presented by age groups in Table 2 . Among children aged $<1$ year, mean age and all the anthropometric characteristics showed no significant difference between the sexes and strata, except that rural boys were slightly older than the urban boys, and rural boys had a greater mid-upper arm circumference than the rural girls. Among children aged 1-3 years, boys in rural areas had significantly greater weight and BMI and all boys had a significantly greater head circumference than their female counterparts. On the other hand, urban girls had significantly greater skinfolds than their male counterparts. Urban children also had significantly greater tricipital skinfolds than their rural counterparts. Among children aged 4-6 years, similar anthropometric characteristics were observed between the sexes and strata, except for boys having a greater waist circumference but a lower subscapular skinfold than the girls. Among children aged 7-12 years, all the anthropometric characteristics were generally higher in urban children than in their rural counterparts, although significant differences were not observed for some variables. In this age group, girls had significantly greater skinfolds than the boys in both the urban and rural areas, while urban boys had a greater waist circumference than the girls.

The prevalence of overnutrition and undernutrition is reported in Tables 3 and 4 . The prevalence of thinness was similar throughout the various age groups, except in the age group 1-3 years, in which a lower prevalence was observed (Table 3). The prevalence of obesity, on the other hand,

Table 4. Percentage of stunted children in urban and rural areas by age group

\begin{tabular}{|c|c|c|c|c|c|}
\hline & $\begin{array}{c}0.5-0.9 \\
\text { years }\end{array}$ & $\begin{array}{c}1.0-3.9 \\
\text { years }\end{array}$ & $\begin{array}{c}4.0-6.9 \\
\text { years }\end{array}$ & $\begin{array}{c}7 \cdot 0-12 \\
\text { years }\end{array}$ & All \\
\hline \multicolumn{6}{|l|}{ Urban } \\
\hline Boys & $24 \cdot 0$ & $17 \cdot 6$ & $9 \cdot 9^{*}$ & $5 \cdot 7$ & $10 \cdot 0^{*}$ \\
\hline Girls & $23.9+\dagger$ & 10.5 & 4.5 & 4.8 & 6.6 \\
\hline All & 23.9 & 14.2 & $7 \cdot 3$ & $5 \cdot 2$ & $8 \cdot 3$ \\
\hline \multicolumn{6}{|l|}{ Rural } \\
\hline Boys & $7 \cdot 3$ & $19 \cdot 1^{\star *}$ & $10 \cdot 8$ & 3.8 & 9.5 \\
\hline Girls & $2 \cdot 6$ & 5.4 & $5 \cdot 3$ & $11 \cdot 1^{\star \star}+\dagger$ & 8.0 \\
\hline All & $4 \cdot 6^{\mathrm{a}}$ & $12 \cdot 2^{b}$ & $7 \cdot 8^{\mathrm{c}}$ & $7 \cdot 3^{b, c}$ & 8.8 \\
\hline
\end{tabular}

$\overline{a, b, c}$ Mean values with unlike superscript letters were significantly different between the age groups based on complex sample logistic regression adjusted for age $(P<0.05)$.

Mean values were significantly different between the sexes by stratum based on complex sample logistic regression adjusted for age: ${ }^{\star} P<0.05$; ${ }^{\star \star} P<0.01$.

Mean values were significantly different between the strata by sex based on complex sample logistic regression adjusted for age: $\dagger+P<0.01$. 

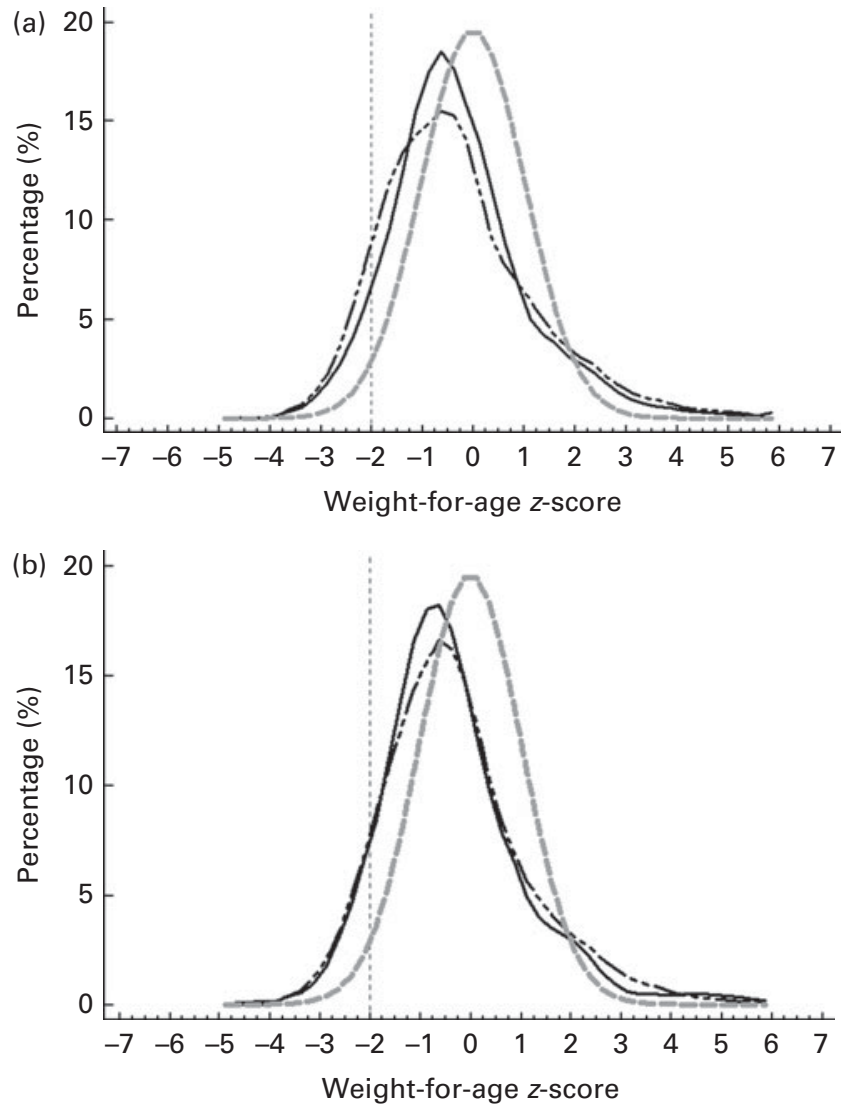

Fig. 3. $z$-Score distribution for weight-for-age of Malaysian children compared with the WHO reference $(--)$ by (a) sex (boys $(-)$ and girls $(-\cdots-)$ ) and (b) strata (urban $(--)$ and rural $(-))$.

was higher in the older age groups. Comparison between the sexes showed that a significantly higher prevalence of thinness and obesity was present in urban boys than in their female counterparts. Comparison between the strata showed that a significantly higher prevalence of obesity was present in urban boys than in their rural counterparts. Table 4 shows that the prevalence of stunting was generally lower in the higher age groups. A higher prevalence of stunting was observed in boys than in the girls, with the difference being significant in the urban population. In the 7-12-year age group, a higher prevalence of stunting was observed in rural girls than in their urban counterparts.

Figs. 3-5 show that the distributions of weight-for-age and height-for-age $z$-scores of Malaysian children were shifted to the left compared with those of the reference population ${ }^{(30,31)}$. For the BMI-for-age $z$-scores, the distribution of Malaysian children appeared to shift only a little to the left, but there were also a small proportion of children for whom the distribution shifted to the right of the reference population.

The levels of the blood parameters of the children by sex, area and age group are detailed in Table 5. Generally, the older age group and urban children exhibited higher values for most of the blood parameters than the younger age group and rural area children, except for vitamin D. After correcting for age, significant differences were observed for certain blood parameters between the sexes from the same area (ferritin and vitamin D) and between the areas for the same sex (vitamin D) between the two age groups.

Table 6 presents the prevalence of anaemia, Fe deficiency, vitamin A deficiency and vitamin D insufficiency by sex, area and age group. Overall, $6 \cdot 6,4 \cdot 4$ and $4 \cdot 4 \%$ of the children had deficit values for $\mathrm{Hb}$, ferritin and vitamin $\mathrm{A}$. In contrast, there was a high prevalence of vitamin D deficiency with $47.5 \%$ having 25-hydroxyvitamin D concentrations $<50 \mathrm{nmol} / 1$, whereby the prevalence among the girls (54.1\%) was significantly higher than that among the boys (41.1\%). The prevalence of anaemia and vitamin A deficiency was higher in rural areas than in the urban areas, whereas the prevalence of Fe deficiency and vitamin D deficiency was lower in the rural areas. A higher prevalence of anaemia and vitamin A deficiency was observed among younger children, whereas older children were found to have a poorer ferritin and vitamin D status when compared with their younger counterparts.

The mean energy and macronutrient intakes of Malaysian children by age group and residence strata are presented in Table 7. As expected, the energy and macronutrient intakes were higher in the older age groups. The mean energy and macronutrient intakes were generally higher for boys than for the girls in the same age group except for the 0.5-0.9year and 1-3-year age groups, where they were similar between the sexes. Overall, there was no significant difference in mean energy and macronutrient intakes between rural and
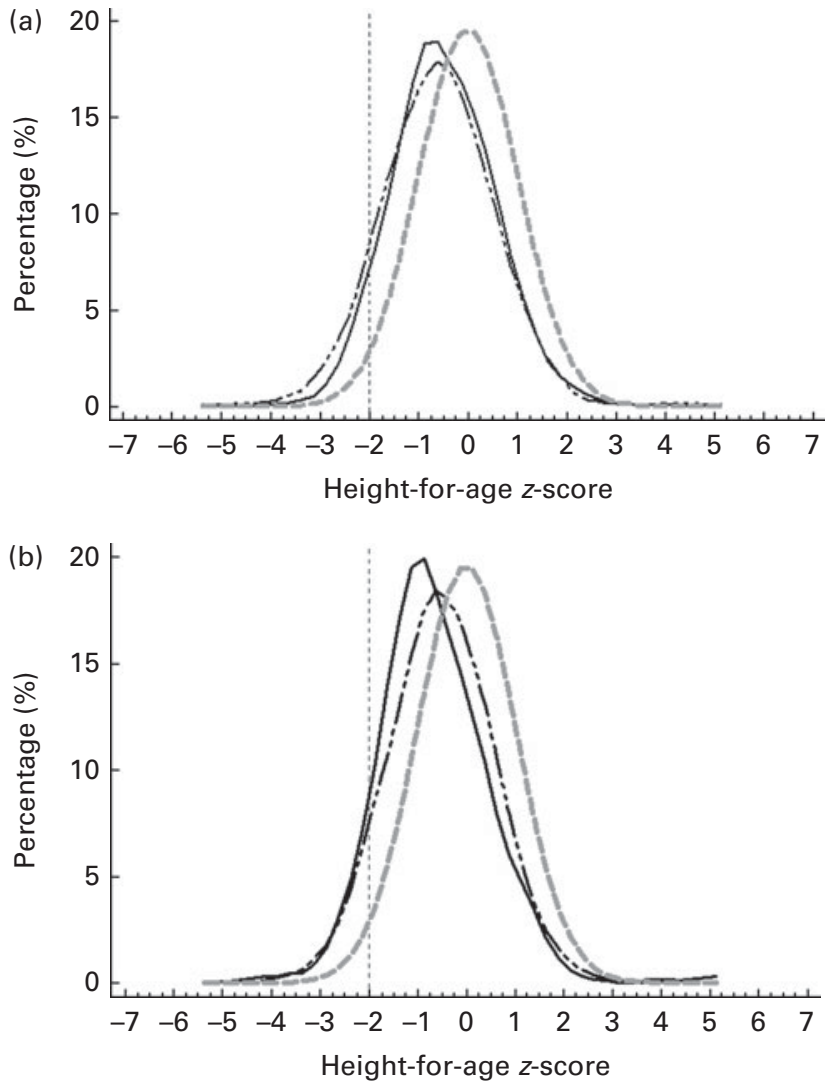

Fig. 4. $z$-Score distribution for height-for-age of Malaysian children compared with the WHO reference (-..-) by (a) sex (boys (-..-) and girls (-)) and (b) strata (urban (-.--) and rural (-)). 

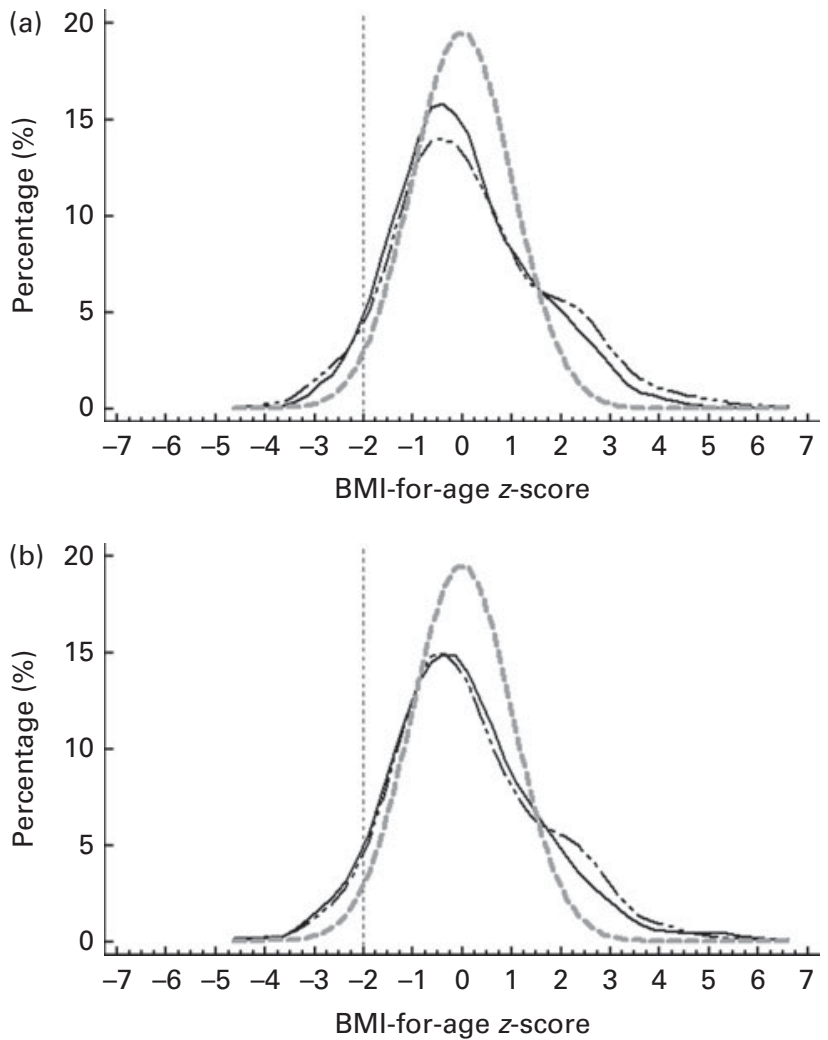

Fig. 5. $z$-Score distribution for BMI-for-age of Malaysian children compared with the WHO reference (--) by (a) sex (boys (---) and girls (-)) and (b) strata (urban (-.-) and rural (-)).

urban children across the age groups. However, significant differences in mean energy and certain macronutrient intakes were found when comparing rural and urban children of the same sex in the 1-3-year age group.

Table 8 reports the micronutrient intakes according to age group and residence strata. As expected, micronutrient intakes were higher in the older age groups. There was no obvious difference in intakes between the sexes except for $\mathrm{Ca}, \mathrm{Fe}$ and vitamin $\mathrm{C}$ intakes in certain age groups. Ca intake of girls aged 0.5-0.9 years and $\mathrm{Fe}$ intake of girls aged 1-3 years were higher than those of their male counterparts. On the other hand, vitamin $C$ intake of rural girls aged 1-3 years and urban girls aged 7-12 years was significantly higher than that of their counterparts from the same area. No differences in micronutrient intakes between the urban and rural areas were observed, except in the youngest and oldest age groups. In the age group 7-12 years, $\mathrm{Ca}, \mathrm{Fe}$ and vitamin $\mathrm{C}, \mathrm{A}$ and $\mathrm{D}$ intakes of the urban girls were higher than those of the rural girls. Besides, Ca, Fe and vitamin D intakes of rural boys aged 0.5-0.9 years were significantly higher than those of their urban counterparts.

In general, the percentage of children not achieving the Malaysian $\mathrm{RNI}^{(48)}$ for nutrients across the age groups was lower than 20\%, except for energy, Ca and vitamin D (Table 9). Approximately 30\% of the children did not achieve the energy recommendations, while nearly 50\% did not achieve the $\mathrm{Ca}$ and vitamin $\mathrm{D}$ recommendations. In urban areas, significantly more boys aged $7-12$ years did not achieve the Malaysian RNI for energy and vitamin C compared with their female counterparts. On the other hand, in rural areas, the percentage of girls aged 4-6 years who did not achieve the Malaysian RNI for vitamins C and A was more than double that of the boys. On comparing the urban and rural areas, it was observed that there were a higher percentage of girls aged 7-12 years in rural areas who did not achieve the Malaysian RNI for Fe and vitamins A and D compared with their urban counterparts. On the other hand, the percentage of urban children aged $1-3$ years not achieving the vitamin A recommendations was more than four times that of the rural counterparts.

\section{Discussion}

The findings of SEANUTS Malaysia will be deliberated and compared with those of other national studies as well as those of other neighbouring countries.

\section{Anthropometric status of Malaysian children}

Among infants aged $<1$ year, the anthropometric parameters did not differ much between the sexes as well as between the urban and rural locations. Sex and urban/rural differences became more apparent for those aged $\geq 1$ year, especially in the oldest age group ( $7-12$ years). Among the primary schoolaged children, urban children evidently had a better nutritional status than their rural counterparts. An analysis of data from thirty-six developing countries has concluded that lower urban malnutrition is due to more favourable socio-economic conditions, which in turn lead to better caring practices for children $^{(49)}$

Overall, the prevalence of overweight (9.8\%) and obesity $(11 \cdot 8 \%)$ was higher than that of thinness $(5 \cdot 4 \%)$ and stunting (8.4\%). $z$-Score distribution curves for weight-for-age and height-for-age shows that Malaysian children are skewed to the left of the WHO reference, both for boys and girls as well as urban and rural. However, for BMI-for-age $z$-score distribution, the curve was dissimilar in that although to a certain extent it was skewed to the left, above $2 \mathrm{sD}$, there were also a certain percentage of children for whom the distribution was above the WHO reference, producing a wider spread for the BMI-for-age distribution. The rightward spread above the reference population indicates that there are a subgroup of children who are unusually big and implies that there are a proportion of children in the population who are of a better nutritional status and probably also a higher socio-economic status than the rest

Contrary to the present findings, the NHMS 2011 has reported that the prevalence of thinness (12.2\%) was higher than that of obesity (6.1\%) among children aged $<18$ years $^{(50)}$. Similarly, previous NHMS 2006 report has also stated that the prevalence of underweight (13.2\%) was higher than that of overweight $(5 \cdot 4 \%)^{(26)}$. It must, however, be noted that both the NHMS 2006 and NHMS 2011 reports had used the 2000 United States Centers for Disease Control and Prevention (CDC) growth charts ${ }^{(51)}$, while the present 
Table 5. Blood parameters of boys and girls by area of residence

(Mean values with their standard errors)

\begin{tabular}{|c|c|c|c|c|c|c|c|c|}
\hline \multirow[b]{3}{*}{ Variables } & \multicolumn{4}{|c|}{ Urban } & \multicolumn{4}{|c|}{ Rural } \\
\hline & \multicolumn{2}{|c|}{ Boys } & \multicolumn{2}{|c|}{ Girls } & \multicolumn{2}{|c|}{ Boys } & \multicolumn{2}{|c|}{ Girls } \\
\hline & Mean & SE & Mean & SE & Mean & SE & Mean & SE \\
\hline \multicolumn{9}{|l|}{$4.0-6.9$ years } \\
\hline $\mathrm{Hb}(\mathrm{g} / \mathrm{l})$ & $125 \cdot 9$ & 1.7 & $126 \cdot 0$ & $2 \cdot 2$ & $125 \cdot 5$ & 1.8 & $121 \cdot 6$ & 1.7 \\
\hline Ferritin $(\mu \mathrm{g} / \mathrm{l})$ & 42.5 & $2 \cdot 7$ & $52 \cdot 3^{*}$ & 3.5 & $42 \cdot 8$ & 4.1 & $41 \cdot 7$ & 4.8 \\
\hline Vitamin $A(\mu \mathrm{mol} / \mathrm{l})$ & 1.00 & 0.04 & 0.95 & 0.03 & 0.99 & 0.04 & 1.00 & 0.04 \\
\hline Vitamin D (nmol/l) & $65 \cdot 1$ & $3 \cdot 0$ & $59 \cdot 1$ & $2 \cdot 7$ & $75 \cdot 5^{\star \star} \dagger$ & $3 \cdot 2$ & $62 \cdot 7$ & $3 \cdot 6$ \\
\hline \multicolumn{9}{|l|}{$7 \cdot 0-12$ years } \\
\hline $\mathrm{Hb}(\mathrm{g} / \mathrm{l})$ & 133.1 & 0.8 & $132 \cdot 0$ & 0.7 & 131.9 & 1.3 & $132 \cdot 6$ & 1.0 \\
\hline Ferritin ( $\mu \mathrm{g} / \mathrm{l})$ & 48.4 & 2.9 & $49 \cdot 8$ & 3.6 & 59.8 & $5 \cdot 4$ & $47 \cdot 7$ & $3 \cdot 8$ \\
\hline Vitamin $A(\mu \mathrm{mol} / \mathrm{l})$ & 1.04 & 0.02 & 1.08 & 0.03 & 1.04 & 0.04 & 1.06 & 0.03 \\
\hline Vitamin D (nmol/l) & $54 \cdot 3^{\star \star \star}$ & 1.6 & $43 \cdot 2$ & 1.4 & $56 \cdot 6^{\star \star *}$ & 1.9 & $46 \cdot 4$ & 1.5 \\
\hline
\end{tabular}

study analysed nutritional status based on the WHO growth references ${ }^{(30,31)}$. The application of the WHO 2006 growth standards may have produced a lower prevalence of underweight and a higher prevalence of stunting and overweight compared with that of the 2000 CDC growth charts $^{(52)}$. A reanalysis of the NHMS 2006 data for children aged $<5$ years indicated $14.9 \%$ thinness and $6.4 \%$ overweight based on the WHO 2006 BMI-for-age standards and 17.2\% stunting based on the WHO 2006 height-for-age standards ${ }^{(17)}$.
It would appear that the results of the NHMS 2006 indicated a higher prevalence of undernutrition than that of overnutrition, whereas our data from SEANUTS Malaysia conducted in the years 2010-11 imply that the opposite is true. The reason for this difference is not clear as both studies aimed to be representative of the Malaysian population. However, we speculate that it could be due to the different sampling protocol, whereby the NHMS 2006 sampling was household based, while our survey was sampled at the school, kindergarten and nursery levels. Another possible

Table 6. Prevalence of anaemia, iron deficiency, vitamin A deficiency and vitamin D insufficiency by age group and area of residence

\begin{tabular}{|c|c|c|c|c|c|c|c|}
\hline & \multicolumn{2}{|c|}{$4.0-6.9$ years } & \multicolumn{2}{|c|}{$7 \cdot 0-12$ years } & \multicolumn{2}{|c|}{ All } & \multirow[b]{2}{*}{ All } \\
\hline & Urban & Rural & Urban & Rural & Urban & Rural & \\
\hline \multicolumn{8}{|c|}{ Anaemia§ } \\
\hline Boys & $12 \cdot 9$ & $7 \cdot 4$ & $3 \cdot 7$ & $8 \cdot 0^{*}$ & 6.5 & $7 \cdot 8$ & $6 \cdot 8$ \\
\hline Girls & $9 \cdot 7$ & $33 \cdot 2^{*} \dagger$ & 3.5 & 1.9 & 5.5 & 10.5 & $6 \cdot 4$ \\
\hline All & $11 \cdot 3$ & $17 \cdot 6$ & 3.6 & $5 \cdot 1$ & $6 \cdot 0$ & $9 \cdot 0$ & $6 \cdot 6$ \\
\hline \multicolumn{8}{|c|}{ Fe deficiency\| } \\
\hline Boys & 1.5 & 1.6 & $5 \cdot 3$ & 1.2 & $4 \cdot 1$ & 1.3 & 3.5 \\
\hline Girls & $2 \cdot 4$ & 1.0 & $7 \cdot 6^{*}$ & 3.2 & 5.9 & $2 \cdot 5$ & $5 \cdot 3$ \\
\hline All & $2 \cdot 0$ & 1.3 & $6 \cdot 4$ & $2 \cdot 2$ & $5 \cdot 0$ & 1.9 & 4.4 \\
\hline \multicolumn{8}{|c|}{ Vitamin A deficiency } \\
\hline Boys & $3 \cdot 1$ & $14 \cdot 1$ & $4 \cdot 5^{\star}$ & $5 \cdot 6$ & $4 \cdot 1$ & 8.5 & $5 \cdot 1$ \\
\hline Girls & 9.9 & 4.9 & $1 \cdot 1$ & 3.4 & 3.5 & 3.7 & 3.6 \\
\hline All & $6 \cdot 6$ & 10.9 & $2 \cdot 8$ & 4.5 & 3.8 & 6.4 & 4.4 \\
\hline \multicolumn{8}{|c|}{ Vitamin D insufficiency§§ } \\
\hline Boys & 35.5 & $10 \cdot 8$ & $48 \cdot 2$ & 38.9 & $44.3 \dagger$ & 29.5 & $41 \cdot 1$ \\
\hline Girls & $33 \cdot 7+\dagger$ & $27 \cdot 2$ & $66 \cdot 7^{\star}$ & $52 \cdot 9^{*}$ & $56 \cdot 2^{*}$ & $45 \cdot 4^{\star}$ & $54 \cdot 1$ 扞 \\
\hline All & 34.6 & $17 \cdot 9$ & $57 \cdot 3$ & $45 \cdot 6$ & $50 \cdot 2$ & 36.9 & 47.5 \\
\hline
\end{tabular}

Mean values were significantly different between the sexes by stratum based on complex sample logistic regression adjusted for age: ${ }^{\star} P<0.05$.

Mean values were significantly different between the strata by sex based on complex sample logistic regression adjusted for age: $† P<0.05$; †† $P<0.01$.

Mean values were significantly different between the sexes based on complex sample logistic regression adjusted for age: $\ddagger \ddagger P<0.01$.

$\S$ Cut-off values of $\mathrm{Hb}$ concentration based on WHO/UNICEF/UNU (2001) ${ }^{(33)}$; children aged $<5$ years, $<11$ g/l; children aged $5-11$ years, $<11.5 \mathrm{~g} / \mathrm{l}$; children aged $12-13$ years, $<12 \mathrm{~g} / \mathrm{l}$.

$\|$ Cut-off values of serum ferritin concentration based on WHO/UNICEF/UNU (2001)(33): children aged $<5$ years, $<12 \mu \mathrm{g} / \mathrm{l}$; children aged $\geq 5$ years, $<15 \mu \mathrm{g} / \mathrm{l}$.

ๆ Deficiency is defined as serum retinol concentration $<0.7 \mu \mathrm{mol} / /$ based on WHO $(2009)^{(10)}$

$\S \S$ Insufficiency is defined as 25 -hydroxyvitamin D concentration $<50 \mathrm{nmol} / /$ based on Misra et al. ${ }^{(37)}$. 
reason could be the different geographical areas covered and the larger number of participants in the NHMS 2006. Also, the different time periods during which the two surveys were conducted could possibly explain the lower prevalence of undernutrition and higher prevalence of overnutrition in the present survey. Khor et al. ${ }^{(17)}$ found a similar pattern, where the prevalence of underweight and stunting was lower and that of overweight was higher when comparing the NHMS 2006 data for children aged $<5$ years with the results of the year 2000 Ministry of Health, Malaysia (MOH)/UNICEF survey in the same age group. Among primary school children, two surveys conducted by Universiti Kebangsaan Malaysia (UKM) in the years 2001 and 2008 had also found that the prevalence of overweight and obesity had increased from $20 \cdot 7$ to $26.4 \%$, whereas that of thinness decreased, although not by much, from 9.7 to $9.5 \%$ over the 7 -year period ${ }^{(53)}$.

\section{Micronutrient deficiencies in Malaysian children}

Fe deficiency and anaemia were identified as the most important factors leading to micronutrient malnutrition in Malaysia based on persistence and prevalence ${ }^{(54)}$. The findings of the present study demonstrate that the overall prevalence of $\mathrm{Fe}$ deficiency and anaemia is 4.4 and $6.6 \%$, respectively, which according to the $\mathrm{WHO}^{(34)}$ is at a low level of public health significance for anaemia. The Fe status of the children is, therefore, encouraging, and it is in concordance with a recent study carried out among urban school children in Kuala Lumpur, which has found that the prevalence of both Fe deficiency and anaemia is $2 \cdot 2 \%{ }^{(16)}$. However, a higher prevalence ranging from 48.5 to $62.0 \%$ has been reported by other local studies mostly in rural areas ${ }^{(55-57)}$. Detailed analysis of our own data indicated a higher prevalence of anaemia in Sabah $(13.2 \%)$ than in Peninsular Malaysia (5.8\%) and Sarawak (4.0\%). The difference in study locations and study age groups may have contributed to the variance in results.

Moderate-to-high levels of Fe deficiency and anaemia have long been one of the predominant findings of nutrition surveys among children in Southeast Asia. When compared with data from other countries, the present results show that the prevalence of Fe deficiency and anaemia among Malaysian children is relatively low. A study conducted in northeast Thailand, which involved 567 school children, has reported $31.0 \%$ of the children to be anaemic ${ }^{(58)}$, while in Vietnam the prevalence of Fe deficiency and anaemia among preschool children is 9.8 and $55.6 \%$, respectively ${ }^{(59)}$.

The lower prevalence of anaemia among the children may be due to national programmes implemented by the Ministry of Health, such as the Programme on the Rehabilitation of Malnourished Children that targets families with income below the poverty line that had underweight children aged $<5$ years ${ }^{(60)}$. Under this programme, food baskets containing essential food items, as well as Fe and multivitamin supplements, are distributed to eligible recipients on a monthly basis. The Family Health Clinics also routinely disseminate nutrition education on food preparation techniques for a balanced diet, which includes the promotion of Fe-rich foods ${ }^{(61)}$. 
The prevalence of vitamin A deficiency in the present study was lower than that reported by other Malaysian studies. In the present study, $4.4 \%$ of the children were found to have vitamin A deficiency and the prevalence of vitamin A deficiency in rural areas (6.4\%) was higher than that in urban areas (3.8\%). Earlier studies conducted in Malaysia have reported a range of prevalence rates from $3.9 \%$ in a sample of children aged $<5$ years ${ }^{(62)}$ to $27 \cdot 4 \%$ among aboriginal school children aged $7-12$ years ${ }^{(63)}$. Based on $\mathrm{WHO}^{(64)}$ definition, vitamin A deficiency among our population of children is considered a mild public health problem, that is, between 2 and $9 \%$ having retinol concentration $<0.70 \mu \mathrm{mol} / \mathrm{l}$.

In other parts of the world, vitamin A deficiency remains a public health problem. A high prevalence of vitamin A deficiency has been reported among Vietnamese primary school girls, whereby $35.7 \%$ of rural children and $21.4 \%$ of urban children exhibited marginal retinol stores (0.35$0.7 \mu \mathrm{mol} / \mathrm{l})^{(65)}$. A study conducted among pre-school children in the southern coastal area of central Jawa in Indonesia has reported that $52 \%$ of the children had a very low serum retinol concentration $(0.35-0.7 \mu \mathrm{mol} / \mathrm{l})^{(66)}$. The lower prevalence in Malaysia than in the surrounding countries may be due to the relatively better socio-economic and nutritional status of Malaysian children.

Despite Malaysia being a tropical country located right next to the equator and exposed to sunshine all year round, findings from the present study reveal that a large proportion of children (47.5\%) have vitamin D insufficiency. Similarly, a recent local study conducted among urban school children has documented $37 \cdot 1 \%$ of the children to have an insufficient vitamin D status ${ }^{(16)}$. As mentioned by Chailurkit et al. ${ }^{(67)}$, a low vitamin $\mathrm{D}$ level is not an uncommon problem even in countries that receive abundant sunshine. Numerous studies have shown a poor vitamin D status among children in tropical countries, including Qatar $(68.8 \%)^{(13)}$, India $(10.8 \%)^{(68)}$ and Saudi Arabia $(58.8 \%)^{(69)}$.

Inadequate dietary intake of vitamin $\mathrm{D}$ and low sunlight exposure are likely to be the main contributing factors for the poor vitamin D status in the study population. Most foods are poor sources of vitamin D, with the exception of egg yolk and certain types of fish and seafood. In Malaysia, not many foods are fortified with vitamin $\mathrm{D}$ and these are confined to certain brands of margarines and beverages only. Hence, it is not likely that children in Malaysia can obtain sufficient vitamin D from dietary sources alone ${ }^{(16)}$. Malaysian children also tend to spend more time engaged in indoor sedentary activities, such as doing homework, reading, playing computer games and watching television ${ }^{(70)}$. They avoid being outdoors during the day due to the hot and humid weather, thus leading to an impact on outdoor activities and sunlight exposure.

A difference in vitamin D status between urban and rural children was clearly demonstrated in the present study. Environmental factors such as air pollution may play a contributory role, where tropospheric ozone, an efficient absorber of UV, is a common air pollutant found in urban cities that may indirectly reduce the availability of sunlight to 
Table 9. Percentage of subjects not achieving Malaysian Recommended Nutrient Intake recommendations of macronutrients and micronutrients by age group and area of residence

\begin{tabular}{|c|c|c|c|c|c|c|c|c|c|c|c|c|c|c|c|}
\hline & \multicolumn{3}{|c|}{$0.5-0.9$ years } & \multicolumn{3}{|c|}{$1.0-3.9$ years } & \multicolumn{3}{|c|}{$4 \cdot 0-6 \cdot 9$ years } & \multicolumn{3}{|c|}{$7 \cdot 0-12$ years } & \multicolumn{3}{|c|}{ All } \\
\hline & Boys & Girls & All & Boys & Girls & All & Boys & Girls & All & Boys & Girls & All & Boys & Girls & All \\
\hline \multicolumn{16}{|l|}{ Urban } \\
\hline Energy & 33.4 & $41 \cdot 6$ & 37.4 & $33.8 \dagger \dagger$ & $29 \cdot 6$ & $31 \cdot 8$ & $35 \cdot 3$ & $38 \cdot 1$ & $36 \cdot 7$ & $39.7^{\star}$ & $31 \cdot 7$ & $35 \cdot 7$ & $37 \cdot 1$ & 33.0 & $35 \cdot 1$ \\
\hline Protein & - & $16 \cdot 1$ & $7 \cdot 8$ & 1.6 & 3.4 & $2 \cdot 4$ & 0.4 & 1.4 & 0.9 & 0.6 & $1 \cdot 2$ & 0.9 & $2 \cdot 1$ & $2.9 \dagger$ & 2.5 \\
\hline $\mathrm{Ca}$ & $19 \cdot 3$ & 14.5 & $17 \cdot 0$ & $25 \cdot 2$ & $29 \cdot 7$ & $27 \cdot 4$ & $43.4 \dagger$ & 43.5 & 43.5 & 63.4 & $66 \cdot 6$ & $65 \cdot 0$ & 48.5 & 51.4 & 49.9 \\
\hline $\mathrm{Fe}$ & $62.9 \dagger$ & 64.7 & 63.8 & $11.1 \dagger$ & 5.6 & 8.4 & 1.0 & 1.8 & 1.4 & $12 \cdot 8$ & $10 \cdot 1$ & 11.5 & 11.0 & 8.7 & 9.9 \\
\hline Vitamin C & - & - & - & $7 \cdot 3$ & $3 \cdot 6$ & 5.5 & 4.0 & $4 \cdot 1$ & 4.0 & $13 \cdot 4^{\star}$ & 8.9 & $11 \cdot 2$ & $9 \cdot 3^{*}$ & $6 \cdot 4$ & 7.9 \\
\hline Vitamin A & - & $5 \cdot 0$ & $2 \cdot 4$ & $7 \cdot 7$ & $10 \cdot 1+\dagger$ & 8.9 & $9 \cdot 1$ & $8 \cdot 4$ & $8 \cdot 8$ & $4 \cdot 3$ & $3 \cdot 1$ & 3.7 & $6 \cdot 1$ & $6 \cdot 0$ & $6 \cdot 0$ \\
\hline Vitamin D & $45 \cdot 4$ & $28 \cdot 3$ & $37 \cdot 1$ & 35.6 & 38.9 & $37 \cdot 2$ & 51.6 & $51 \cdot 2$ & 51.4 & $52 \cdot 0$ & $52 \cdot 6$ & $52 \cdot 3$ & $48 \cdot 0$ & 48.5 & $48 \cdot 3$ \\
\hline \multicolumn{16}{|l|}{ Rural } \\
\hline Energy & 8.4 & $40 \cdot 2$ & $26 \cdot 2$ & $21 \cdot 3$ & 11.0 & $16 \cdot 1$ & $29 \cdot 6$ & $26 \cdot 9$ & $28 \cdot 1$ & $40 \cdot 8$ & $36 \cdot 8$ & 38.9 & $32 \cdot 7$ & $27 \cdot 2$ & 30.0 \\
\hline Protein & - & - & - & 0.4 & 0.8 & 0.6 & 0.4 & 0.9 & 0.6 & $1 \cdot 2$ & $1 \cdot 7$ & 1.4 & 0.8 & 1.4 & 1.1 \\
\hline $\mathrm{Ca}$ & $5 \cdot 0$ & 7.9 & $6 \cdot 6$ & 24.0 & $19 \cdot 1$ & 21.5 & 33.3 & 44.9 & 39.5 & $66 \cdot 2$ & $74 \cdot 8$ & $70 \cdot 3$ & $47 \cdot 2$ & $51 \cdot 1$ & $49 \cdot 1$ \\
\hline $\mathrm{Fe}$ & $19 \cdot 0$ & $34 \cdot 3$ & $27 \cdot 6$ & 2.5 & $2 \cdot 2$ & $2 \cdot 4$ & $2 \cdot 1$ & 4.4 & $3 \cdot 3$ & $13 \cdot 2$ & $18.0 \dagger$ & $15 \cdot 5$ & $8 \cdot 1$ & $10 \cdot 6$ & 9.3 \\
\hline Vitamin C & - & - & - & 1.7 & 1.3 & 1.5 & $1 \cdot 8$ & $5 \cdot 6^{\star}$ & 3.8 & $12 \cdot 1$ & $13 \cdot 6$ & $12 \cdot 8$ & $7 \cdot 0$ & 8.1 & 7.5 \\
\hline Vitamin A & $5 \cdot 0$ & - & $2 \cdot 2$ & $4 \cdot 3$ & $2 \cdot 1$ & $3 \cdot 2$ & 3.9 & $11.0^{*} \dagger$ & $7 \cdot 7$ & $10 \cdot 2 \dagger \dagger$ & 9.6††† & 9.9 & $7 \cdot 2$ & $7 \cdot 6$ & 7.4 \\
\hline Vitamin D & $11 \cdot 7$ & $17 \cdot 8$ & $15 \cdot 1$ & $32 \cdot 7$ & $29 \cdot 3$ & $31 \cdot 0$ & $42 \cdot 5$ & 52.5 & $47 \cdot 9$ & 59.9 & $66 \cdot 7 \dagger \dagger$ & $63 \cdot 2$ & $48 \cdot 3$ & $52 \cdot 0$ & $50 \cdot 1$ \\
\hline
\end{tabular}

Mean values were significantly different between the sexes by stratum based on complex sample logistic regression adjusted for age: ${ }^{\star} P<0 \cdot 05$

Mean values were significantly different between the strata by sex based on complex sample logistic regression adjusted for age: $\dagger P<0.05$; $\dagger \dagger P<0.01 ; \dagger \dagger P<0.001$.

urban populations ${ }^{(71)}$. Besides, cultural factors such as clothing practices may also limit the capacity of the skin to synthesise vitamin $\mathrm{D}$. This is more evident in girls than in boys, especially among Muslim girls whose headscarves and long dresses generally allow for greater body coverage and may explain in part the finding that more girls exhibited a poorer vitamin $\mathrm{D}$ status than boys.

\section{Dietary intake of Malaysian children}

The energy and macronutrient intakes of boys were higher than those of girls in the present study, whereas micronutrient intakes were quite similar between both the sexes, with the exception of $\mathrm{Ca}$ intake in youngest age groups and $\mathrm{Fe}$ and vitamin $\mathrm{C}$ intakes in the other age groups. The sex differences in energy and macronutrient intakes could be explained by the food choices and preferences of boys and girls, where boys preferred high-energy-dense foods compared with the girls. A study among 4205 children aged 9-12 years has reported that less desirable foods such as pre-sugared cereals, cakes, confectionery, burgers and sausages were eaten more by boys than by girls ${ }^{(72)}$. Besides that, Cooke \& Wardle ${ }^{(73)}$ also concluded that boys like fatty and sugary foods, meat, processed meat products and eggs more than girls do.

The dietary intake levels of rural children among the infant and pre-schooler groups appeared to be better than those of their urban counterparts. However, in the oldest age group, the micronutrient intakes of rural girls such as Fe, vitamins A and D intakes, were significantly lower than those of the urban girls. Inadequate consumption of nutrient-dense foods among the rural girls may be one of the contributing factors for this phenomenon. This finding is in agreement with that of a study on 667 Korean children aged 7-12 years that reported that dietary intakes of calories, Fe and niacin in the rural areas were lower than those in the urban areas ${ }^{(74)}$.

Overall, the dietary intake of the children was not compatible with that recommended by the Malaysian RNI, especially for $\mathrm{Ca}$ and vitamin D. Vitamin D and Ca intakes of about $50 \%$ of the children were below the recommendations. The percentage of children who did not achieve the Malaysian RNI for Ca was higher among the school-aged children than among infants and toddlers. This percentage of inadequate intake was found to be higher than the $17-35 \%$ found in previous studies ${ }^{(75,76)}$. Milk as one of the food sources rich in Ca and vitamin D is the dominant food for infants and toddlers. The low $\mathrm{Ca}$ and vitamin $\mathrm{D}$ intakes across the age group may be related to a reduction in milk consumption $^{(77)}$.

The percentage of rural girls in the oldest age group who did not achieve the Malaysian RNI for Fe was significantly higher than that of the boys. The lower intake of Fe in 7-12year-old girls was found to match with the higher prevalence of Fe deficiency in this age group found in the present study. Moreover, the onset of menarche usually occurring between 10 and 12 years may partially explain the higher prevalence of Fe deficiency in the older girls ${ }^{(78)}$. However, differences in food choices could be one of the contributing factors. In the present study, girls may have consumed foods with a lower bioavailability of Fe when compared with the boys and hence may have an increased risk of anaemia. Besides, food choices of older girls may also have been affected by factors such as body image and diet control, which are unfavourable for their nutrient and energy intakes ${ }^{(79)}$.

\section{Strengths and limitations}

SEANUTS Malaysia has several strengths. Topmost among the strengths is the fact that this survey is comprehensive and measured a broad range of nutrition-related parameters. Apart from those reported in the present paper (anthropometry, blood biochemistry and dietary parameters), physical activity, bone health, blood pressure, cognitive development, child health, child food habits, including breast-feeding and complementary feeding in younger children, as well as fatty acid profile and many other blood biochemical parameters ${ }^{(24)}$ 
were assessed in a nationally representative sample. The methods used in the present study were developed and pre-tested rigorously and validated to ensure a sound methodology and to enable comparison across the four countries.

This is the first study carried out in Malaysia, and among the few in the literature ${ }^{(17,26,50)}$, to cover a wide paediatric age range from 6 months to 12 years old. The present study provides a valuable database and adds to the scanty literature on the nutritional status of Malaysian infants and children.

A limitation of this survey is the small number of infants recruited. This may be due to the fact that the parents of young children are more anxious and concerned about the welfare of their infants and are less likely to provide consent for participation. Consequently, the sample for young children, especially infants, was slightly smaller in proportion than the population. Additionally, it was also very difficult to obtain parental consent for blood collection from children aged $<4$ years. Hence, we had only sixteen children aged 2-3.9 years who gave blood, and we had to omit them from the data analysis. Another limitation is the overestimation of portion sizes in dietary assessment, as the FFQ was proxy-reported by the mothers or main carers. Some mothers had difficulty in estimating the portion sizes of the foods consumed by their children ${ }^{(80,81)}$. Hence, dependence on third parties (carers or mothers) to report the intakes of the children may have led to a biased estimation of portion sizes ${ }^{(82)}$.

In conclusion, SEANUTS Malaysia has provided an enormous amount of important data regarding the nutritional status of children aged 12 years. On the whole, the findings of the present study reveal that both sides of malnutrition exist among the children of Malaysia. However, overnutrition is more prevalent than undernutrition. While micronutrient deficiencies, such as anaemia and vitamin A deficiency, appear to be lower than those reported previously, vitamin $\mathrm{D}$ insufficiency is highly prevalent in both the sexes and both urban and rural areas and affects nearly half of the childhood population of Malaysia. Dietary intakes of Ca, vitamin D and energy are also of concern, where nearly half of the population did not achieve the Malaysian RNI for Ca and vitamin D and more than $30 \%$ did not achieve the energy recommendations. The results of this survey provide the much-needed information for the planning and implementation of the National Plan of Action for Nutrition in Malaysia. Strategies for improving the nutritional status of Malaysian children cannot remain focused only on undernutrition; they also need to put emphasis on approaches for the prevention of overweight and obesity as well as vitamin D insufficiency.

\section{Acknowledgements}

The study was funded by Royal FrieslandCampina Innovation (UKM-Dutch Lady Project Code: NN-072-2009). The authors thank all the subjects and their parents for their participation and cooperation during the course of the present study. They are grateful to the school principals, teachers and administrators for their support and assistance. The researchers, data collection team, enumerators and all those involved in this project are acknowledged and much appreciated for their effort and dedication. They are also grateful to Nguyen Thu $\mathrm{Ha}$ and Ang Yeow Nyin for their assistance in data analysis and, last but not the least, also to Paul Deurenberg for his invaluable advice throughout the project.

The authors' contributions were as follows: B. K. P., M. D. S. H., S. N. S., J. E. W., A. K. N., S. B. B., A. T. R. and L. O. N. conceived and designed the study; B. K. P., B. K. N., M. D. S. H., S. N. S. and I. K. analysed and interpreted the data, as well as drafted and revised the manuscript. All authors critically reviewed and approved the final version of the manuscript for publication. The authors declare no known conflicts of interest. Any opinions, findings, conclusions or recommendations expressed in this publication are those of the authors and do not necessarily reflect the views of FrieslandCampina.

This paper was published as part of a supplement to the British Journal of Nutrition, the publication of which was supported by an unrestricted educational grant from Royal FrieslandCampina. The papers included in this supplement were invited by the Guest Editor and have undergone the standard journal formal review process. They may be cited. The Guest Editor appointed to this supplement is Dr Panam Parikh. The Guest Editor declares no conflict of interest.

\section{References}

1. Popkin BM (2001) Nutrition in transition: the changing global nutrition challenge. Asia Pac J Clin Nutr 10, S13-S18.

2. Popkin BM (2011) Contemporary nutritional transition: determinants of diet and its impact on body composition. Proc Nutr Soc 70, 82-91.

3. Popkin BM, Adair LS \& Ng SW (2012) Global nutrition transition and the pandemic of obesity in developing countries. Nutr Rev 70, 3-21.

4. Caballero B (2002) Global patterns of child health: the role of nutrition. Ann Nutr Metab 46, Suppl. 1, 3-7.

5. Uauy R, Kain J, Mericq V, et al. (2008) Nutrition, child growth, and chronic disease prevention. Ann Med 40, 11-20.

6. Khambalia AZ, Lim SS, Gill T, et al. (2012) Prevalence and sociodemographic factors of malnutrition among children in Malaysia. Food Nutr Bull 33, 31-42.

7. Khor GL \& Zalilah MS (2003) Dual forms of malnutrition in the same households in Malaysia - a case study among Malay rural households. Asia Pac J Clin Nutr 12, 427-438.

8. World Health Organization (2010) World Health Statistics 2010. Geneva: WHO. http://www.who.int/whosis/whostat/ 2010/en/index.html.

9. World Health Organization (2012) World Health Statistics 2012. Geneva: WHO. http://www.who.int/gho/publications/world_ health_statistics/2012/en/index.html.

10. World Health Organization (2009) Global Prevalence of Vitamin A Deficiency in Populations at Risk 1995-2005. WHO Global Database on Vitamin A Deficiency. Geneva: WHO.

11. World Health Organization (2008) Worldwide Prevalence of Anaemia 1993-2005: WHO Global Database on Anaemia. Geneva: WHO.

12. Holick MF \& Chen TC (2008) Vitamin D deficiency: a worldwide problem with health consequences. Am J Clin Nutr 87, Suppl., 1080S-1086S

13. Bener A, Al-Ali M \& Hoffmann GF (2009) High prevalence of vitamin D deficiency in young children in a highly sunny 
humid country: a global health problem. Minerva Pediatr 61, 15-22.

14. Gessner BD, Plotnik J \& Muth PT (2003) 25-Hydroxyvitamin D levels among healthy children in Alaska. J Pediatr 143, 434-437.

15. Gilbert-Diamond D, Baylin A, Mora-Plazas M, et al. (2010) Vitamin D deficiency and anthropometric indicators of adiposity in school-age children: a prospective study. Am J Clin Nutr 92, 1446-1451.

16. Khor GL, Chee WSS, Shariff ZM, et al. (2011) High prevalence of vitamin D insufficiency and its association with BMI-for-age among primary school children in Kuala Lumpur, Malaysia. BMC Public Health 11, 95.

17. Khor GL, Noor Safiza MN, Jamalludin AB, et al. (2009) Nutritional status of children below five years in Malaysia: anthropometric analyses from the Third National Health and Morbidity Survey III (NHMS, 2006). Mal J Nutr 15, 121-136.

18. Ismail MN, Ruzita AN, Norimah AK, et al. (2009) Prevalence and trends of overweight and obesity in two cross-sectional studies of Malaysia children, 2002-2008. In MASO 2009 Scientific Conference on Obesity: Obesity and Our Environment, 12-13 August 2009, Kuala Lumpur.

19. UNICEF (2010) Nutrition Country Profile for Malaysia. http:// www.childinfo.org/country_profiles.php?input $=90$

(accessed May 2012)

20. Hasan I, Zulkifle M \& Ansari AH (2011) An assessment of nutritional status of the children of government Urdu higher primary schools of Azad Nagar and its surrounding areas of Bangalore. Arch Appl Sci Res 3, 167-176.

21. Albertson AM \& Tobelmann RC (1993) Ten-year trend of energy intakes of American children ages $2 \pm 10$ years. Ann N Y Acad Sci 699, 250-252.

22. Brady LM, Lindquist CH, Herd SL, et al. (2000) Comparison of children's dietary intake patterns with US dietary guidelines. BrJ Nutr 84, 361-367.

23. World Health Organization (1966) The Assessment of the Nutritional Status of the Community. Monograph Series no. 53. Geneva: WHO.

24. Schaafsma A, Deurenberg P, Calame W, et al. (2013) Design of the South East Asian Nutrition Survey: a four country multi-stage cluster design study. BrJ Nutr 110, S2-S10.

25. World Health Organization (1986) Sample Size Determination: A User's Manual. Geneva: WHO.

26. Institute for Public Health (2008) Nutritional Status. Report of the Third National Health and Morbidity Survey 2006 (NHMS III). Kuala Lumpur: IPH, Ministry of Health.

27. Department of Statistics Malaysia (2010) Population, Housebold and Living Quarters, Malaysia 2010. Putrajaya: Department of Statistics.

28. Ministry of Education Malaysia (2010) Malaysia Educational Statistics 2010. Putrajaya: Ministry of Education.

29. Marfell-Jones M, Olds T, Stewart A, et al. (2006) International Standards for Anthropometric Assessment. Potchefstroom: International Society for the Advancement of Kinanthropometry (ISAK).

30. World Health Organization (2006) WHO Child Growth Standards. Geneva: WHO. http://www.who.int/childgrowth (accessed October 2010).

31. World Health Organization (2007) Growth Chart for Children 5-19 years. Geneva: WHO. http://www.who.int/growthref/ en/ (accessed October 2010).

32. World Health Organization (2010) WHO Anthro for Personal Computers Manual: Software for Assessing Growth and Development of the World's Children. Geneva: WHO.
33. World Health Organization (2009) WHO AnthroPlus for Personal Computers Manual: Software for Assessing Growth of the World's Children and Adolescents. Geneva: WHO.

34. World Health Organization (2001) Iron Deficiency Anaemia: Assessment, Prevention, and Control. Geneva: WHO.

35. World Health Organization (2011) Haemoglobin Concentrations for the Diagnosis of Anaemia and Assessment of Severity. Vitamin and Mineral Nutrition Information System. Geneva: WHO. http://www.who.int/vmnis/indicators/ haemoglobin.pdf (accessed July 2011).

36. World Health Organization (2011) Serum Ferritin Concentrations for the Assessment of Iron Status and Iron Deficiency in Populations. Vitamin and Mineral Nutrition Information System. Geneva: WHO. http://www.who.int/vmnis/indicators/ serum_ferritin.pdf (accessed July 2011).

37. Misra M, Pacaud D, Petryk A, et al. (2008) Vitamin D deficiency in children and its management: review of current knowledge and recommendations. Pediatrics 122, 398-417.

38. Ooi SY, Ng BK, Ong WW, et al. (2010) Development of food frequency questionnaire among infants in Malaysia. In Abstract and Poster Presented at 25th Scientific Conference of the Nutrition Society of Malaysia, 25-26 March 2010, p. 132. Kuala Lumpur, Malaysia: Nutrition Society of Malaysia.

39. Irma HA, Poh BK, Norimah AK (2011) Validation of proxyreported food frequency questionnaires (FFQ) in assessing dietary intake among children aged 6 months to 23 months. In Abstract and Poster Presentation at 26th Scientific Conference of the Nutrition Society of Malaysia, 24-25 March 2011, pp. 98-99. Kuala Lumpur, Malaysia: Nutrition Society of Malaysia.

40. Ho PS, Poh BK, Norimah AK, et al. (2011) Validation of proxy-reported food frequency questionnaire to assess dietary intake among children aged 2 to 6 years old. In Abstract and Poster Presentation at 26th Scientific Conference of the Nutrition Society of Malaysia, 24-25 March 2011, p. 98. Kuala Lumpur, Malaysia: Nutrition Society of Malaysia.

41. Fatihah F, Ng BK, Ong WW, et al. (2011) Development of food frequency questionnaire for Malaysian children aged 7-9 years. In Abstract and Poster Presented at 25th Scientific Conference of the Nutrition Society of Malaysia, 25-26 March 2010, p. 117. Kuala Lumpur, Malaysia: Nutrition Society of Malaysia (Won the First Prize in the Poster Competition).

42. Hazwanie H, Poh BK, Norimah AK (2011) Validation of food frequency questionnaire for dietary intake assessment among children aged 7-12 years old. In Abstract and Poster Presentation at 26th Scientific Conference of the Nutrition Society of Malaysia, 24-25 March 2011, pp. 97-98. Kuala Lumpur, Malaysia: Nutrition Society of Malaysia.

43. Tee ES, Ismail MN, Nasir MA, et al. (1997) Nutrient Composition of Malaysian Foods, 4th ed. Kuala Lumpur: Institute for Medical Research.

44. Department of Nutrition (2000) The Composition of Foods Commonly Eaten in Singapore 2000. Singapore: Ministry of Health.

45. Taki M, Mizuno K, Murase M, et al. (2010) Maturational changes in the feeding behaviour of infants - a comparison between breast-feeding and bottle-feeding. Acta Paediatr 99, 61-67.

46. Puwastien P, ASEAN Network of Food Data System (2000) ASEAN Food Composition Tables. Bangkok, Thailand: Institute of Nutrition, Mahidol University.

47. Chong YM, Poh BK, Ng BK, et al. (2011) Development of Nutrient Calculator for Children's Food Frequency 
Questionnaire. In Abstract and Poster Presentation at 26th Scientific Conference of the Nutrition Society of Malaysia, 24-25 March 2011, pp. 91-92. Kuala Lumpur, Malaysia: Nutrition Society of Malaysia.

48. National Coordinating Committee on Food and Nutrition (2005) Recommended Nutrient Intakes of Malaysia. A Report of the Technical Working Group on Nutritional Guidelines. Putrajaya: Ministry of Health Malaysia.

49. Smith LC, Ruel MT \& Ndiaye A (2005) Why is child malnutrition lower in urban than in rural areas? Evidence from 36 developing countries. World Dev 33, 1285-1305.

50. Institute for Public Health (2011) Non Communicable Diseases. Report of the National Health and Morbidity Survey 2011 (Volume II). Kuala Lumpur: IPH, Ministry of Health.

51. Kuczmarski RJ, Ogden CL, Guo SS, et al. (2000) CDC growth charts for the United States: methods and development. National Center for Health Statistics. Vital Health Stat 11, $1-190$.

52. Mei Z, Ogden CL, Flegal KM, et al. (2008) Comparison of the prevalence of shortness, underweight, and overweight among US children aged 0 to 59 months by using the CDC 2000 and the WHO 2006 growth charts. J Pediatr 153, 622-628.

53. Ruzita AT, Nurunnajiha N, Wong JE, et al. (2009) Nutritional Status and Dietary Habits of Primary School Children in Peninsular Malaysia: Comparison of the 2001/02 Survey with the 2007/08 Survey. Report for UKM-Nestle Research Project. Kuala Lumpur: Universiti Kebangsaan Malaysia.

54. Khor GL (2002) Micronutrient deficiency and its alleviation: the case of Malaysia. Asia Pac J Clin Nutr 11, S377-S381.

55. Ngui R, Lim YAL, Liam CK, et al. (2012) Association between anaemia, iron deficiency anaemia, neglected parasitic infections and socioeconomic factors in rural children of West Malaysia. PLoS Negl Trop Dis 6, e1550.

56. Nor Aini U, Al-Mekhlafi HM, Azlin M, et al. (2007) Serum iron status in Orang Asli children living in endemic areas of soil-transmitted helminths. Asia Pac J Clin Nutr 16, $724-730$.

57. Al-Mekhlafi MH, Surin J, Atiya AS, et al. (2008) Anaemia and iron deficiency anaemia among aboriginal school children in rural Peninsular Malaysia: an update on a continuing problem. Trans $R$ Soc Trop Med Hyg 102, 1046-1052.

58. Thurlow RA, Winichagoon P, Green T, et al. (2005) Only a small proportion of anemia in northeast Thai school children is associated with iron deficiency. Am J Clin Nutr 82, $380-387$.

59. Nhien NV, Khan NC, Ninh NX, et al. (2008) Micronutrient deficiencies and anemia among preschool children in rural Vietnam. Asia Pac J Clin Nutr 17, 48-55.

60. Rokiah D (2009) Children nutrition policies and programmes in the Ministry of Health Malaysia. Mal J Nutr 15, S2.

61. Khor GL (2005) Micronutrient status and intervention programs in Malaysia. Food Nutr Bull 26, Suppl. 2, S281-S285.

62. Ministry of Health (2000) Hemoglobin and Serum Retinol Level Amongst Children Under 5 Years of Age. Report of a MOH-UNICEF Study. Kuala Lumpur: Division of Family Health Development.

63. Al-Mekhlafi HM, Surin J, Sallam AA, et al. (2010) Giardiasis and poor vitamin A status among aboriginal school children in rural Malaysia. Am J Trop Med Hyg 83, 523-527.

64. World Health Organization (1996) Indicators for Assessing Vitamin A Deficiency and Their Application in Monitoring and Evaluation Intervention Programmes. Geneva: WHO. http://www.who.int/nutrition/publications/micronutrients/ vitamin_a_deficiency/WHONUT96.10.pdf.

65. Mai TT, Hung NK, Kawakami M, et al. (2003) Micronutrient status of primary school girls in rural and urban areas of South Vietnam. Asia Pac J Clin Nutr 12, 178-185.

66. Hadi H, Stoltzfus RJ, Dibley MJ, et al. (2000) Vitamin A supplementation selectively improves the linear growth of Indonesian preschool children: results from a randomized controlled trial. Am J Clin Nutr 71, 507-513.

67. Chailurkit L, Aekplakorn W \& Ongphiphadhanakul B (2011) Regional variation and determinants of vitamin D status in sunshine-abundant Thailand. BMC Public Health 11, 853.

68. Marwaha RK, Tandon N, Reddy DRHK, et al. (2005) Vitamin $\mathrm{D}$ and bone mineral density status of healthy schoolchildren in northern India. Am J Clin Nutr 82, 477-482.

69. Mansour MMHK \& Alhadidi KM (2012) Vitamin D deficiency in children living in Jeddah, Saudi Arabia. Indian J Endocrinol Metab 16, 263-269.

70. Ismail MN, Norimah AK, Ruzita AT, et al. (2003) Nutritional Status and Dietary Habits of Primary School Children in Peninsular Malaysia. Final Report for UKM-Nestle Research Project. Kuala Lumpur: Universiti Kebangsaan Malaysia.

71. Holick MF (1995) Environmental factors that influence the cutaneous production of vitamin D. Am J Clin Nutr 61, 638S-645S.

72. Hackett AF, Gibbon M, Sratton G, et al. (2002) Dietary intake of 9-10-year-old and 11-12-year-old children in Liverpool. Public Health Nutr 5, 449-455.

73. Cooke LJ \& Wardle J (2005) Age and gender differences in children's food preferences. Br J Nutr 93, 741-746.

74. Kim SH, Kim JY \& Keen CL (2005) Comparison of dietary patterns and nutrient intakes of elementary schoolchildren living in remote rural and urban areas in Korea: their potential impact on school performance. Nutr Res 25, 349-363.

75. Muhammad Faiz AA \& Naleena Devi M (2012) Nutritional status and eating practices among children aged $4-6$ years old in selected urban and rural kindergarten in Selangor, Malaysia. Asian J Clin Nutr 4, 116-131.

76. Elias SM, Hashim Z, Marjan ZM, et al. (2007) Relationship between blood lead concentration and nutritional status among Malay Primary School Children in Kuala Lumpur, Malaysia. Asia Pac J Public Health 19, 29-37.

77. Du XQ, Greenfield H, Fraser DR, et al. (2002) Milk consumption and bone mineral content in Chinese adolescent girls. Bone 30, 521-528.

78. Thane CW, Batesa CJ \& Prentice A (2002) Menarche and nutritional status in pubescent British girls. Nutr Res 22, 423-432.

79. Nowak M (1998) The weight-conscious adolescent: body image, food intake, and weight-related behaviour. $J$ Adolesc Health 23, 389-398.

80. Reinaerts E, de Nooijer J \& de Vries NK (2007) Parental versus child reporting of fruit and vegetable consumption. Int J Behav Nutr Phys Act $4,33$.

81. Klohe DM, Clarke KK, George GC, et al. (2005) Relative validity and reliability of a food frequency questionnaire for a triethnic population of 1-year-old to 3-year-old children from low income families. $J$ Am Diet Assoc 105, 727-734.

82. Sherwood NE (2008) Diet assessment in children and adolescents. In Handbook of Childhood and Adolescent Obesity, pp. 73-89 [E Jejalian and RG Steele, editors]. Minneapolis: Health Partners Foundation. 